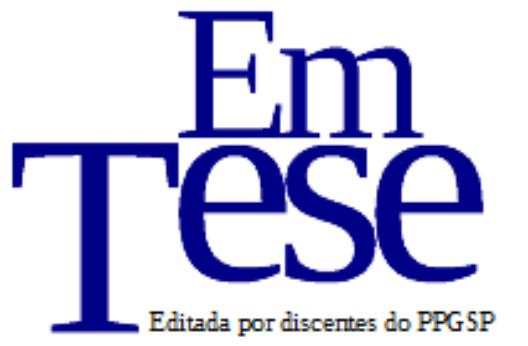

UFSC

PPG SP PROG RAMA DE

PÓS-GRADUAÇÃO EM

Sociologia

Política

v. 15, n. 1 (parte II), p.189-222, mar./abr., 2018.

http://dx.doi.org/10.5007/1806-5023.2018v15n1p189

\title{
As leis de declaração de utilidade pública na ALMG: do escopo normativo- institucional aos outputs políticos ${ }^{1}$
}

Bruno Arcas Lopes dos Santos ${ }^{2}$ Julio Cesar Guimarães de Paula ${ }^{3}$ Victor Araújo ${ }^{4}$

Resumo: O presente trabalho argumenta que as Leis de Declaração de Utilidade Pública (LDUP) são instrumentos de vinculação entre os parlamentares proponentes e a suas respectivas bases eleitorais. Dentro do roll de atuação dos deputados estaduais, tendo em vista seu baixo custo de aprovação e a oportunidade de estabelecer contato com a sua constituency, as LDUP têm sido um dos principais instrumentos legislativos da assembleia mineira. As Leis de Declaração de Utilidade Pública são uma alternativa pouco utilizada nos estudos legislativos para a mensuração do comportamento particularista dos deputados em nível subnacional. Os resultados sugerem covariação entre a proposição de Leis de Declaração de Utilidade Pública e o envio de Emendas Parlamentares. Nós argumentamos que essa relação pode ser explicada pela natureza similar dos dois tipos de atuação parlamentar. Ambos fazem parte do mesmo "Pacote Institucional", compondo o universo de atuação particularista dos parlamentares analisados.

Palavras-Chave: Particularismo - Utilidade Pública - Conexão Eleitoral

The laws of declaration of public utility in the ALMG: from the normative-institutional scope to the political outputs

\begin{abstract}
The present paper argues that the Public Utility Declaration Laws (LDUP) are instruments of linkage between the proponent parliamentarians and their respective electoral bases. Within the roll of action of the state deputies, in view of its low cost of approval and the opportunity to establish contact with its constituency, the LDUP have been one of the main legislative instruments of the mining assembly. The Public Utility Declaration Laws are a little used alternative in the legislative studies for the measurement of the particularistic behavior of the deputies in subnational level. The results suggest covariation between the proposition of Laws of Public Utility Declaration and the sending of Parliamentary Amendments. We argue that this relationship can be explained by the similar nature of the two types of parliamentary performance. Both are part of the same "Institutional Package", composing the universe of particularist action of the analyzed parliamentarians.
\end{abstract}

Keywords: Particularism. Public Utility. Electoral Connection

\footnotetext{
1 (cc) EY Esta obra está licenciada com uma Licença Creative Commons Atribuição 4.0 Internacional.

${ }^{2}$ Mestrando em Ciência Política pela UFMG e Pesquisador do Centro de Estudos Legislativos DCP/UFMG. E-mail: brarcas@gmail.com

${ }^{3}$ Mestre em Ciência Política pela UFMG. Pós-graduando em Estatística Aplicada pela mesma instituição e Pesquisador do Centro de Estudos Legislativos DCP/UFMG. E-mail: juliogcpaula@gmail.com

${ }^{4}$ Graduado em Ciências Sociais (UFMG), Mestre em Ciência Política (USP) e doutorando em Ciência Política (USP). E-mail: victor.asaraujo@gmail.com.
} 


\section{Introdução}

Este trabalho assume que os representantes - na intenção de garantir a permanência em seus cargos - estabelecem vínculos com a sua constituency, ou ainda, estabelecem vínculos com potenciais novos eleitores. Utilizamos a definição de conexão eleitoral proposta por Mayhew (1974), na qual os parlamentares empreendem ações que beneficiem diretamente seus eleitores na expectativa de que estes retribuam com votos no momento eleitoral.

Assumindo que os parlamentares tendem a enviar benefícios para os seus distritos eleitorais informais, utilizamos as Leis de Declaração de Utilidade Pública (LDUP) como indicador de conexão eleitoral. Argumentamos que as LDUP são instrumentos de vinculação entre os parlamentares proponentes e a suas respectivas bases eleitorais. Dentro do roll de atuação dos deputados estaduais, tendo em vista seu baixo custo de aprovação e a oportunidade de estabelecer contato com a sua constituency, as LDUP têm sido um dos principais instrumentos legislativos da assembleia mineira. A natureza centralizada do arranjo federativo configurado no Brasil a partir da constituição de 1988 garante a união tanto a prerrogativa de legislar exclusivamente sobre a maior parte das matérias constitucionais (SOUZA, 2005), quanto concede ao governo federal instrumentos para constranger a atuação dos legisladores subnacionais (ARRETCHE,2010; MONTEIRO NETO, 2014). Neste contexto, matérias com efeito distributivo geograficamente delimitado ganham centralidade na atuação dos legisladores estaduais (TOMIO; RICCI, 2010).

A despeito da análise de proposição das LDUP tratar-se de uma alternativa pouco utilizada nos estudos legislativos para a mensuração do comportamento distributivista dos deputados em nível subnacional, do universo das proposições legislativas à disposição dos deputados estaduais brasileiros, a proposição das LDUP é uma atividade recorrente entre os parlamentares subnacionais. No caso da Assembleia Legislativa de Minas Gerais (ALMG), seus parlamentares se destacam pela proporção de utilização desse instrumento legislativo.

A partir da análise das proposições dos deputados da 16 ${ }^{a}$ legislatura (2007-2011) da ALMG, reunimos evidências empíricas que nos permitem validar o argumento de que as Leis de Utilidade Pública são um mecanismo de conexão eleitoral. Ainda que exista uma substancial variação no número de proposições executadas por cada deputado, esse mecanismo de conexão eleitoral é utilizado por praticamente todos os parlamentares. De forma complementar, cabe questionar quais os fatores relacionam-se com essa variação. 
Os testes econométricos realizados neste trabalho indicam que a proposição das LDUP não varia em função de fatores como o posicionamento ideológico dos parlamentares, a clivagem governo oposição, ou ainda em relação ao padrão de votação dos deputados - seus níveis de concentração ou dominância. Os resultados sugerem covariação entre a proposição de Leis de Declaração de Utilidade Pública e o envio de Emendas Parlamentares. Nós argumentamos que essa relação pode ser explicada pela natureza similar dos dois tipos de atuação parlamentar. Ambos fazem parte do mesmo "Pacote Institucional", compondo o universo de atuação particularista dos parlamentares analisados.

Além dessa introdução, este capítulo está dividido em mais três partes. Na próxima seção, apresentamos o referencial teórico do trabalho e o problema de pesquisa. Além disso, é discutido as LDUP a partir do contexto da produção legal e de seus mecanismos institucionais voltados para a lógica da conexão eleitoral. A seção seguinte discuti os benefícios fiscais LDUP e sua vinculação a um "Pacto Institucional" particularista a disposição dos deputados estaduais. $\mathrm{Na}$ terceira seção, testamos nossos argumentos através da identificação dos padrões de associação espacial e da operacionalização do modelo de regressão binomial negativo. Por fim, na última seção, discutimos os resultados e realizamos apontamentos acerca da temática investigada.

\section{Legislativos Subnacionais e as Leis de Declaração de Utilidade Pública}

\subsection{Referencial teórico e a construção do problema de pesquisa}

discutir os fundamentos da organização legislativa dos estados e como os parlamentares interagem com essas instituições. Os aspectos idiossincráticos dos estados da federação recebeu o olhar mais sistemático de Lima Junior (1983). O autor atestou a importância das análises voltadas para entendimento da organização política nos níveis subnacionais de governo. Tais abordagens se justificariam pelo fato de estados e municípios apresentarem realidades políticas próprias, estas legitimadas pelo caráter federalista de nossa república. O autor utilizou dois indicadores (Número Efetivo de Paridos e Fragmentação Eleitoral), com o objetivo de classificar os subsistemas partidários estaduais e chegou a uma tipologia que atestou a existência de padrões variados na formatação dos sistemas partidários nos estados. 
Essa constatação de Lima Júnior (1983), por si só já legitimaria o estudos das unidades subnacionais. Porém, a disciplina pouco evoluiu no sentido de examinar ou mesmo contestar a tese do autor.

Contudo, a partir do processo de redemocratização do país um novo olhar se recaiu sobre os níveis subnacionais de governo, é nesse contexto que o temos o trabalho de Abrúcio (1998)). O autor procurou operacionalizar as possibilidades e os limites do presidencialismo de coalizão para os estados. A conclusão a que chega é que a política estadual seria marcada por uma forte concentração de poderes nas mãos dos governadores. Os mesmos contavam com fortes poderes de agenda e com elevados recursos orçamentários. Essa relação assimétrica entre os poderes era ratificada por um “pacto homologatório”. Na medida em que o Legislativo, marcado por uma debilidade institucional, homologava a agenda do Executivo, em troca de benefícios particularista, segundo o autor essências para a manutenção da carreira política dos parlamentares. Foi a partir de tal diagnóstico que Abrúcio (1998) elaborou o conceito de "ultrapresidencialismo estadual”. Com isso, os mecanismos de “checks and balances" entre os poderes seriam praticamente inexistentes. Análises mais recentes têm mostrado uma crescente perda de responsabilidades dos níveis subnacionais de governo, principalmente a partir de meados da década de 1990 (TOMIO; RICCI, 2008; TOMIO; RICCI, 2010; ARRETCHE, 2009). Contudo, a análise de Abrúcio (1998) se tornou referência para estudiosos que se interessam pelo nível subnacional de governo.

As análises contidas em Santos (2001) se dedicaram em explorar aspectos relativos ao processo decisório, a relação Executivo-Legislativo, além de confrontarem as explicações correntes para a Câmara dos Deputados com os arranjos institucionais observados nas casas legislativas subnacionais. Uma conclusão importante do livro é a existência de uma variação institucional significativa, entre os legislativos estaduais, e entre estes e o legislativo federal. Aspectos relacionados à produção legal e a organização interna das casas apresentam aspectos idiossincráticos importantes.

O artigo de Castro, Anastasia e Nunes (2009) cumpre importante papel na discussão sobre os incentivos que orientam a representação parlamentar em doze legislativos estaduais. $\mathrm{O}$ objetivo do artigo é analisar o efeito de variáveis como: competição política, filiação partidária, posicionamento ideológico, tipos de apoiadores consistentes sobre o comportamento legislativo dos deputados estaduais. A partir da sistematização de dois índices (graus de competição na arena eleitoral e arena legislativa) os autores classificaram os estados da federação e 
fortaleceram a ideia de Lima Junior (1983) da existência de diversos subsistemas políticos no nível subnacional brasileiro. A análise empírica mostrou que variáveis como: posicionamento ideológico e tipos de apoiadores consistentes apresentam impacto positivo sobre o comportamento particularista dos parlamentares analisados.

Tomio de Ricci $(2009 ; 2010)$ a, (2012a) e ( partir da análise da produção legal realizada no âmbito dos legislativos estaduais chegaram a importantes conclusões, uma delas se relaciona ao fato da atuação dos deputados ser diretamente informada pelas regras institucionais. As restrições institucionais aliadas as fortes prerrogativas Legislativas do Executivo, formatariam um poder Legislativo estadual institucionalmente esvaziado. Consequentemente os legisladores se dedicariam a políticas de cunho particularista e de caráter honorífico. Porém, o que aparece de novo nas análises dos autores, é que há um espaço para um protagonismo dos legisladores em materiais de escopo mais amplo. Esse achado nos diz que a dinâmica dos legislativos subnacionais se mostra mais complexa do que a apresentada por Abrúcio (1998). Assim, é no contexto da produção legal dos legislativos subnacionais que ganha relevância as Leis de Declaração de Utilidade Pública (LDUP).

\subsection{As Leis de Declaração de Utilidade Pública: produção legal e conexão eleitoral}

A compreensão do comportamento parlamentar contou com uma grande contribuição teórico-metodológica dos três modelos clássicos de organização legislativa desenvolvidos pela literatura especializada norte-americana. As abordagens distributivista (MAYHEW, 1974), informacional (KREHBIEL, 1991) e partidária (COX e McCUBBINS, 1993) partem do pressuposto que a configuração institucional afeta as preferências dos legisladores. E que os mesmos, como atores racionais, buscariam maximizar suas chances de reeleição. O ponto é que nos três modelos a relação entre representantes e instituições produzem diferentes outputs políticos. Em decorrência disso, a lupa dos estudiosos que se dedicam a desvendar o comportamento parlamentar se recai, ou sobre os fatores exógenos à estrutura legislativa, como por exemplo, o sistema eleitoral, ou sobre os fatores endógenos, tais como as regras formais que orientam a estrutura interna dos trabalhos parlamentares.

O modelo distributivista ${ }^{5}$, em especial o trabalho seminal de David Mayhew (1974), foi pioneiro na análise dos fatores que orientam o comportamento parlamentar. $\mathrm{O}$ argumento se

\footnotetext{
${ }^{5}$ Como dito anteriormente a literatura norte-americana apresenta além do modelo distributivista, os modelos informacional e partidário. Para a teoria informacional as instituições não existem apenas para resolver conflitos de
} 
origina na ideia de conexão eleitoral e na consequente promoção de políticas particularistas para redutos geográficos delimitados (constituents), sendo as ações empreendidas pelos representantes pautadas principalmente pela expectativa de sucesso eleitoral. Embora aspectos como a boa política e a obtenção de postos de poder dentro da organização legislativa também norteiam a ação dos parlamentares sobre a rubrica do modelo distributivista. Apesar do foco na produção de bens particularista, o modelo distributivista não pressupõe uma ação restrita dos parlamentares quanto a utilização das estruturas legislativas. O sistema de comissões e a organização dos gabinetes podem ser formatados para mitigar o custo das transações e possibilitar ganhos de troca por parte dos parlamentares.

À medida que apresentam um caráter descentralizado para sua aprovação diferentemente de outras proposições legislativas que demandam uma articulação mais efetiva entre parlamentares e partidos - dentro do contexto institucional da Assembleia Legislativa de Minas Gerais (ALMG), as Leis de Declaração de Utilidade Pública se configuram como oportunidade real para atuação particularista dos deputados. Para que uma organização da sociedade civil seja beneficiada com o título de utilidade pública estadual, faz-se necessário que algum deputado, comissão ou o governador proponha a qualificação à determinada organização. Dessa forma, qualquer parlamentar pode apresentar às comissões permanentes da Assembleia, proposta de lei - sugerindo a concessão de utilidade pública a alguma organização do seu interesse, desde que está cumpra os requisitos legais. O projeto de Lei de Declaração de Utilidade Pública é analisado conclusivamente pelas comissões permanentes da Assembleia, tramitando em turno único, não sendo submetido ao Plenário ${ }^{6}$.

Em conformidade com o argumento apresentado por Shepsle e Weingast (1987), onde o sistema de comissões reduz os custos das trocas entre os atores, uma vez que desloca as decisões dos espaços multifacetados para arenas internas ao parlamento - marcadas por relativa homogeneidade temática -, constata-se que esse tipo de proposição (LDUP) é um mecanismo propício para atuação individualizada do parlamentar. Ainda sobre a égide do modelo

ordem distributiva. Elas podem adquirir expertise, para produzirem decisões políticas mais informadas. O lócus privilegiado dessas decisões seria o sistema de comissões, tal como nos mostrou o trabalho de Keith Krehbiel (1991). O modelo partidário, que se consolidou como uma terceira geração de estudos sobre a essência do comportamento parlamentar, trás para a análise a importância do partido majoritário como balizador dos trabalhos parlamentares. E como este, a partir do controle da agenda e dos postos legislativos, consegue não apenas resolver problemas de ação coletiva, como também orientar o rumo dos trabalhos congressuais (COX e McCUBBINS, 1993).

${ }^{6}$ Art. 103 do Regimento Interno da ALMG: “Compete às comissões permanentes apreciar, conclusivamente, em turno único, as seguintes proposições - I: projetos de lei que versem sobre: a) declaração de utilidade pública, b) denominação de próprios públicos." 
distributivista, as comissões seriam o lócus privilegiado de atuação paroquial dos representantes devido ao seu caráter indutor da relação entre parlamentares e suas respectivas bases eleitorais.

\section{Leis de Declaração de Utilidade Pública: do contexto institucional aos benefícios}

\section{fiscais}

Contudo, como definir "A Lei de Declaração de Utilidade Pública" do ponto de vista normativo? E quais os benefícios de tal concessão? Podemos definir utilidade pública como título ou qualificação concentrada nas mãos do Estado e direcionada a organizações da sociedade civil. No Brasil existem três níveis de utilidade Pública: Federal, Estadual e Municipal. A matéria foi tratada constitucionalmente no artigo de $n^{\circ} 91$ de 1935, regulamentada pelo decreto 50.517/61 e alterada pelo decreto 3.415/2000. De acordo com o texto da CF 1988, a declaração de utilidade pública federal é feita através de decreto do Poder Executivo e direcionada às organizações juridicamente reconhecidas na forma de associação ou fundação. Os níveis Estadual e Municipal seguem as diretrizes constitucionais, diferenciando-se em relação à forma de regulamentação. No nível subnacional o Poder Legislativo figura como ator relevante no processo de concessão do título.

Em Minas Gerias a Lei Estadual n ${ }^{\circ}$ 12.972, de 27 de julho de 1998, dispõe sobre o reconhecimento de pessoas jurídicas de direito privado sem fins lucrativos como entidades de utilidade pública. Dessa forma, a associação ou a fundação constituída ou em funcionamento no Estado, com o fim exclusivo de servir desinteressadamente à coletividade, pode ser declarada de utilidade pública estadual, desde que comprove:

I - que adquiriu personalidade jurídica;

II - que está em funcionamento há mais de um ano;

III - que os cargos de sua direção não são remunerados;

IV - que seus diretores são pessoas idôneas

Sendo que,

a declaração de cumprimento das exigências previstas nos incisos II, III e IV do caput deste artigo poderá ser firmado pelo Presidente do Conselho Municipal de Assistência social, por Juiz de Direito, Promotor de Justiça, Juiz de Paz, Prefeito, Presidente da Câmara Municipal, Delegado de Polícia, ou por seus substitutos legais, do Município ou da comarca em que a entidade for sediada. (Lei Estadual $n^{\circ} 12.972 / 98$ ). 
Os benefícios de uma organização que detém o título de utilidade pública estadual são: i. isenção de contribuições destinadas à seguridade social; ii. isenção de emolumentos (taxas cobradas por cartórios) e; iii. imunidade fiscal (restrita às entidades de assistência social e educação).

Tendo em vista o exposto acima, como enquadrar as Leis de Declaração de Utilidade Pública no contexto da produção legislativa dos estados brasileiros? A partir do estudo comparado da produção legal no nível subnacional, Tomio e Ricci (2010) procuraram caracterizar as leis utilizando como referência o seu conteúdo (Ver Gráfico 1). Os autores argumentam que o processo legislativo nos estados é marcado pela produção de leis de cunho administrativo, leis que organizam as políticas públicas estaduais e leis honoríficas, nas quais se enquadram as Leis de Declaração de Utilidade Pública. Estas são caracterizadas pelo baixo efeito distributivo e por serem destinadas a redutos geograficamente delimitados (idem, 2010). O gráfico abaixo apresenta uma descrição comparada do tipo de produção legislativa em vinte e uma assembleias brasileiras. As Leis de Declaração de Utilidade Pública figuram como uma importante área de atuação das parlamentares subnacionais, ainda que a sua incidência varie entre os estados investigados. Nesse contexto, a Assembleia Legislativa de Minas Gerais destaca-se como uma das casas onde esse tipo de produção possui maior incidência.

\section{Gráfico 1 - Conteúdo dos projetos de lei de origem do legislativo apresentados}

(2007-2008)

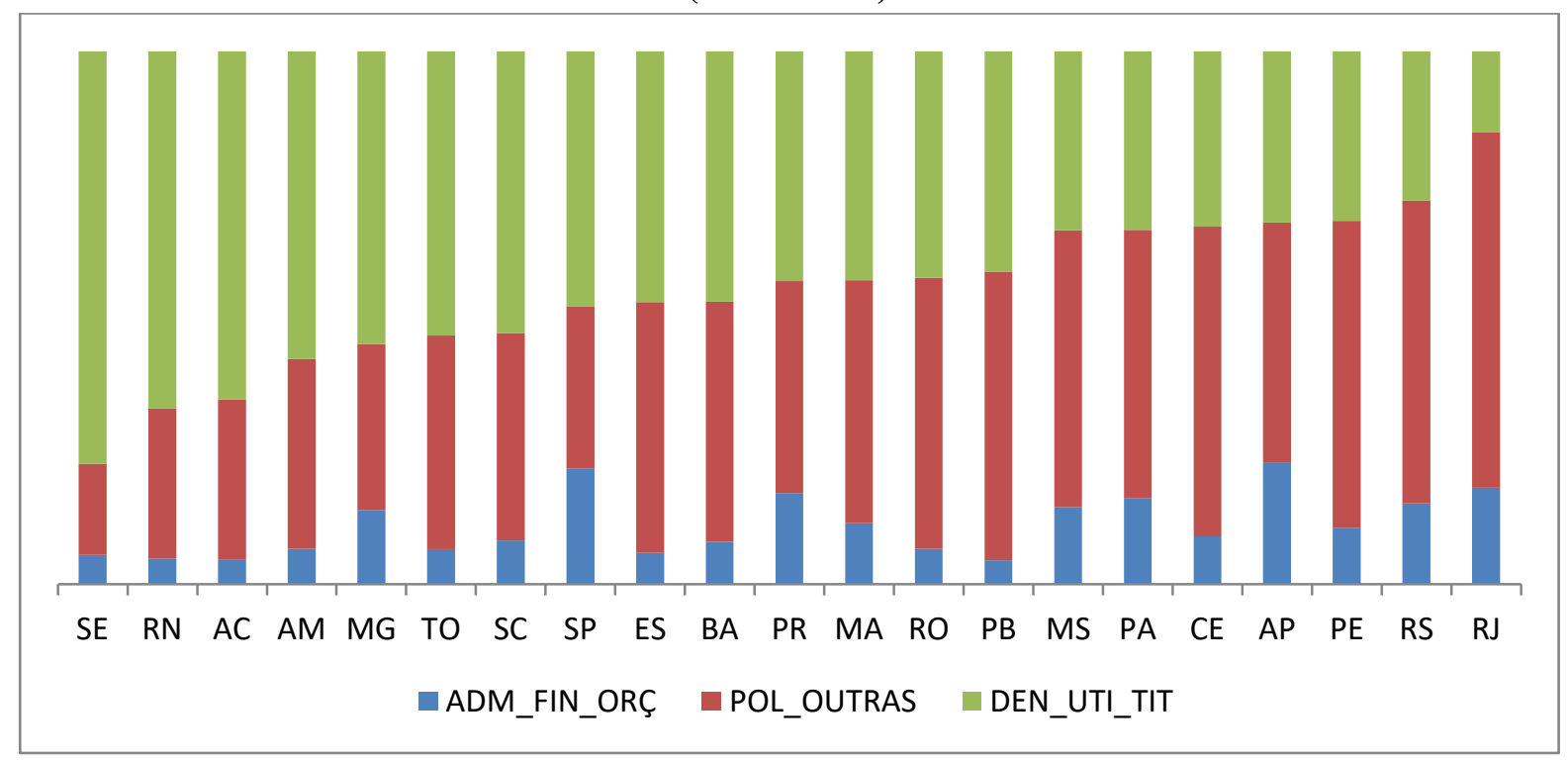

Fonte: elaborado pelos autores a partir de Tomio e Ricci (2010).

As características da produção legislativa nos estados brasileiros tem como referência a engenharia institucional construída no Brasil após a Constituição Federal de 1988 (CF 88). A 
referida constituição conferiu ampla autoridade decisória a União e limitado escopo jurisdicional às unidades subnacionais (ARRETCHE, 2004). Mesmo tendo adotado a descentralização da execução das políticas públicas como principio fundamental, a CF de 1988 conferiu ao poder Executivo federal a prerrogativa de iniciar legislação sobre uma gama de políticas executadas pelos governos estaduais. Ademais, no que se refere às suas competências legislativas, verificase um escasso arcabouço institucional nos níveis subnacionais de governo, permitindo que a união atue de maneira efetiva em praticamente todas as áreas de políticas públicas. A partir dai "esses mecanismos tornam as arenas federais - isto é, o Executivo federal e o Congresso - o foco da vida política nacional, deslocando matérias de estrito interesse local para o centro do sistema político" (idem, 2013: 41).

O argumento de Tomio e Ricci (2010) vai ao encontro do exposto acima. A partir de uma análise longitudinal sobre a distribuição de poderes entre os entes federados, em especial União e estados, os autores chegam a conclusão que a atual constituição guarda consigo traços das elaboradas em períodos autoritários. A CF 1988 redefiniu as prerrogativas da União e dos estados, minimizando o caráter autoritário da CF de 1967/69 e apresentando uma centralização maior do que as anteriores (1934 e 1946). Ainda segundo os autores, "no caso do último período constitucional, como a União possui competência normativa privativa abrangente (CF de 1988, arts. 21 e 23), resta aos estados o papel de produzir norma jurídica muito limitada”. (TOMIO E RICCI. 2010: 13). Assim, além dos executivos estaduais, os legislativos subnacionais também tem suas agendas esvaziadas. O baixo escopo decisório dos parlamentares estaduais conferem aos mesmos baixos recursos institucionais para a produção de políticas públicas. Sob esse prisma, as Leis de Declaração de Utilidade Pública se configuram como a expressão reflexa do quadro institucional que rege, não apenas o legislativo mineiro, como também a agenda de políticas públicas dos níveis subnacionais de governo.

Santos (2012) atesta essa afirmação em estudo que compara os fundamentos da organização legislativa nos estados de Santa Catarina e Rio de Janeiro. O autor também encontra um elevado número de Leis de Declaração de Utilidade Pública aprovadas nas duas casas legislativas, tendo ciência dos benefícios fiscais que essas entidades possuem, Santos (2012) trás um argumento adjacente ao proposto pelo presente trabalho. No qual a concessão de Utilidade Pública a alguma entidade atesta o apoio dos deputados estudais ao movimento associativo, fato que segundo o autor potencializa tais movimentos nos determinados estados. Sem negar a afirmativa de Santos (2012) o presente trabalho pretende enquadrar as Leis de Declaração de Utilidade Pública dentro do "Pacto Institucional" particularista a disposição dos deputados estaduais. 


\subsection{As Leis de Denominação de Utilidade Pública e o "Pacote Institucional" particularista}

O sistema eleitoral brasileiro apresenta duas características importantes para discussão dos mecanismos de conexão eleitoral presentes em nosso sistema político. Assim, o sistema proporcional de lista aberta e os distritos de grande magnitude favorecem a formatação de redutos eleitorais que não necessariamente correspondem aos estados da federação, que pela configuração institucional são os distritos eleitorais. O trabalho de Ames (2003) é sintomático de defesa de que o comportamento legislativo dos deputados seria fortemente marcado pelas características geográficas de sua votação. Sob esse prisma, o presente trabalho parte do pressuposto de que as LDUP fazem parte do "portfólio particularista" a disposição dos deputados na medida em que tem seus benefícios circunscritos a áreas geograficamente delimitadas. Esse "portfólio particularista" é acrescido por mecanismos institucionais como às emendas ao Projeto de Lei Orçamentária Anual (PRAÇA, 2012). Assim, se no âmbito estadual há um esvaziamento das competências legislativas, e uma consequente preponderância institucional do Poder Executivo, as LDUP e às emendas ao orçamento são mecanismos de conexão entre deputados e suas bases. É importante destacar que com relação as LDUP as regras do processo decisório do legislativo mineiro potencializam a edição dessas medidas, já que as mesmas são aprovadas nas comissões e não precisam passar pelo crivo do plenário, fato que como dito anteriormente aumentaria os custos de sua aprovação. Porém, assumi-se também há espaço para a influência da arena eleitoral no comportamento legislativo dos parlamentares e as LDUP seriam uma dos mecanismos de ação particularista dos parlamentares.

\section{Dados e Métodos}

Nesta seção passamos a análise empírica das Leis de Declaração de Utilidade Pública propostas pelos deputados da $16^{\mathrm{a}}$ legislatura (2007-2011) da Assembleia Legislativa de Minas Gerais, a fim de verificar a validade do argumento de que elas são utilizadas pelos deputados como mecanismo de conexão eleitoral. Para tanto, utilizamos a metodologia de análise espacial que permite, através de mapas, descrever e identificar padrões de associação espacial entre as variáveis de estudo. 
Durante a legislatura (fevereiro de 2007 a janeiro de 2011), dos 93 deputados que exerceram mandato ${ }^{7}, 85$ apresentaram pelo menos um projeto de lei para declarar de utilidade pública alguma entidade. Do restante dos deputados que não apresentaram esse tipo de proposição constatou-se que, efetivamente, apenas dois não o fizeram (Pinduca Ferreira e Doutor Ronaldo que exerceram pelo menos um ano de mandato $)^{8}$. Diante desse quadro, realizamos uma amostra desse universo de 85 casos para viabilizar, através de mapas, a exposição da relação entre a votação dos deputados que propuseram LDUP na eleição de 2006 e os municípios sede das entidades beneficiadas pela proposição da lei.

O critério adotado para a escolha da amostra parte da tipologia adotada inicialmente por Ames $(2001)^{9}$ - e posteriormente utilizada por Carvalho (2003) - nos estudos dos padrões de votação dos deputados federais brasileiros nas eleições de 1994 e 1998. O ponto aqui é considerar a relevância dada pela literatura aos padrões de votação enquanto componente explicativo da alocação de políticas com benefícios concentrados como as Leis de Declaração de Utilidade Pública. Segundo Carvalho (2003) "os distintos padrões espaciais de votação observados produzem um conjunto diferenciado de incentivos no que diz respeito ao comportamento legislativo" (CARVALHO, 2003: 91). Assim, os parlamentares foram classificados em duas dimensões de votação: um vetor horizontal (concentração) e outro vertical (dominância). A operacionalização dessas dimensões se deu através dos Índices de concentração e dominância. A concentração (vetor horizontal) sinaliza para uma dimensão mais canônica de conexão eleitoral, na medida em que mensura quão o parlamentar aglutina sua votação nos municípios nos quais é votado. A dominância (vetor vertical) nos coloca outra perspectiva, segundo Carvalho (2003) esse indicador se refere a conformação de mercados eleitorais mais ou menos competitivos e a configuração de redutos eleitorais e seus limites territoriais. Assim, a partir da operacionalização desses dois indicadores tem-se a expectativa de se captar os vínculos entre deputados e eleitorais nas duas dimensões.

\section{Índice concentração}

\footnotetext{
${ }^{7}$ A diferença em relação ao número de 77 deputados eleitos se deve às trocas que ocorreram durante a legislatura devido a afastamento, renúncia ou perda de mandato de algum deputado.

${ }^{8}$ Os outros seis deputados que não propuseram LDUP exerceram mandato apenas um mês (janeiro de 2011) no período de recesso parlamentar.

9 Segundo Avelino et. al. (2011) os índices de concentração eleitoral no Brasil nunca foram objeto de discussão aprofundada. Os autores apontam para o pioneirismo de Ames (1995) na construção desses indicadores e a escolha de sua passa pela possibilidade de comparação com outros trabalhos afeitos ao tema, já que a perspectiva adotada por Ames (1995; 2003) é a perspectiva mais canônica dessa abordagem (AVELINO, et. al., 2011).
} 
Consiste em aplicar o à votação dos deputados o índice de fragmentação de RAE ${ }^{10}$ invertido, desenvolvido por Laakso e Taagepera (1979) e amplamente utilizado pela literatura no cálculo do número efetivo de partidos nos diversos sistemas políticos.

$1 \div \sum p^{2}$, onde $p$ é a proporção de votos obtidos pelo deputado em cada município.

\section{Índice dominância}

Deve-se somar o resultado de $(v i / p i) \times(v i / V)$ obtido em cada um dos municípios onde o deputado obteve mais votos.

$$
\sum_{i}^{n=x}(v i / p i) \times(v i / V)
$$

$i=1,2,3,4 \ldots \mathrm{X}$, os Xi municípios onde o deputado obteve mais votos;

$v i=$ número de votos recebidos pelo deputado no município;

$p i=$ número total de votos válidos para deputado estadual no município;

$V=$ total de votos recebidos pelo deputado em todo o estado.

Aplicando-se os índices propostos, a figura abaixo apresenta os boxplots com a distribuição das LDUP apresentadas pelos deputados, segundo os perfis de votação.

\section{Gráfico 2 - Número de Leis de Declaração de Utilidade Pública propostas pelos deputados de acordo com o perfil de votação (ALMG 2007-2011)}

\footnotetext{
${ }^{10}$ RAE, D (1967). "The Political Consequences of Electoral Laws".
} 


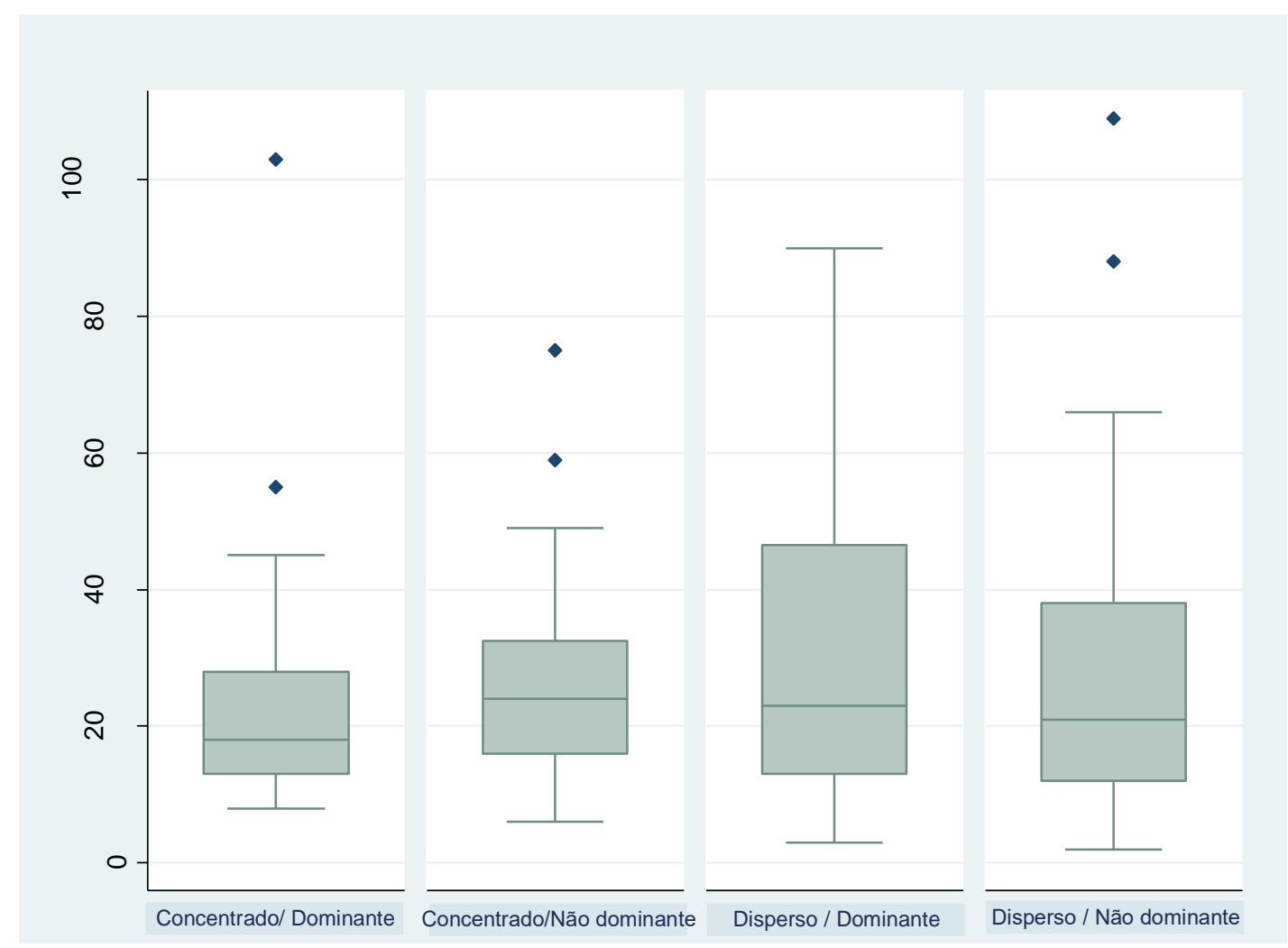

Fonte: elaborado pelos autores

Considerando os dois eixos analisados (horizontal e vertical), a análise do gráfico 2 indica que não há relação clara entre o tipo de votação e o volume de LDUP propostas. O que significa que os parlamentares utilizam esse mecanismo independentemente da natureza concentrada (ou dispersa) ou dominante (ou não dominante) de sua votação. Entretanto, podemos verificar uma grande variação ${ }^{11}$ no envio de LDUP dentro de cada um dos perfis analisados, sugerindo a existência de fatores multivariados responsáveis por essa variação. Antes de analisar tal variação, passemos ao teste do argumento principal levantado por este trabalho.

Diante do objetivo de testar o argumento de que as Leis de Declaração de utilidade pública são mecanismos de conexão eleitoral, selecionamos em cada perfil uma amostra de três ${ }^{12}$ deputados com as seguintes características: o deputado que menos propôs LDUP, o deputado que mais propôs LDUP e o deputado mediano ${ }^{13}$ no que se refere ao número de LDUP propostas. A tabela 1 apresenta os deputados selecionados.

\footnotetext{
${ }^{11}$ No perfil Concentrado/Dominante o número de LDUP propostas variou de 8 a 103, Concentrado/Não Dominante de 6 a 75, Disperso/Dominante de 3 a 90 e Disperso/Não Dominante 2 a 109.

${ }^{12} \mathrm{~A}$ escolha de 3 deputados em cada perfil (12 no total) em detrimento da utilização de todo o universo de 85 deputados, foi feita para viabilizar a apresentação dos mapas.

${ }^{13}$ No perfil Concentrado/Dominante a mediana do número de LDUP propostas pelos deputados foi de 18, Concentrado/Não Dominante 24, Disperso/Dominante 23 e Disperso/Não Dominante 21. Nos casos em que havia mais de um deputado que propôs o mesmo número de LDUP da mediana realizou-se sorteio aleatório. Do mesmo modo, nos casos que não havia deputado que propôs o mesmo número de LDUP da mediana, foi realizado sorteio entre aqueles que propuseram número mais próximo.
} 
Tabela 1 - Deputados Estaduais (MG) selecionados segundo as dimensões de concentração e dominância

\begin{tabular}{|c|c|c|}
\hline Perfil de votação & Deputado & Total LDUP propostas \\
\hline \multirow{3}{*}{ Concentrado / Dominante } & Wander Borges & 103 \\
\hline & Chico Uejo & 8 \\
\hline & Getulio Neiva & 16 \\
\hline \multirow{3}{*}{ Concentrado / Não dominante } & Luiz Humberto Carneiro & 75 \\
\hline & Antonio Genaro Oliveira & 6 \\
\hline & Tenente Lúcio & 24 \\
\hline \multirow{3}{*}{ Disperso / Dominante } & Antonio Carlos & 90 \\
\hline & Reminho Aloise & 3 \\
\hline & Mauri Torres & 25 \\
\hline \multirow{3}{*}{ Disperso / Não dominante } & Padre João & 109 \\
\hline & Marcus Pestana & 2 \\
\hline & Zezé Perrella & 21 \\
\hline
\end{tabular}

Fonte: elaboração própria

Os mapas de 1 à 12 apresentam os resultados. As regiões mais claras representam os municípios em que o deputado obteve menor votação na eleição de 2006 e as mais escuras onde ele obteve maior número de votos. Já os círculos, indicam os municípios sede das entidades que tiveram LDUP propostas pelo deputado.O tamanho do círculo representa a quantidade de LDUP propostas para entidades do município, quanto maior o círculo maior o número de LDUP propostas. 


\section{MAPA 1 - DISTRIBUIÇÃO VOTAÇÃO ELEIÇÃO 2006 E LEIS DUP APRESENTADAS (103) / DEP. ESTADUAL WANDER BORGES}

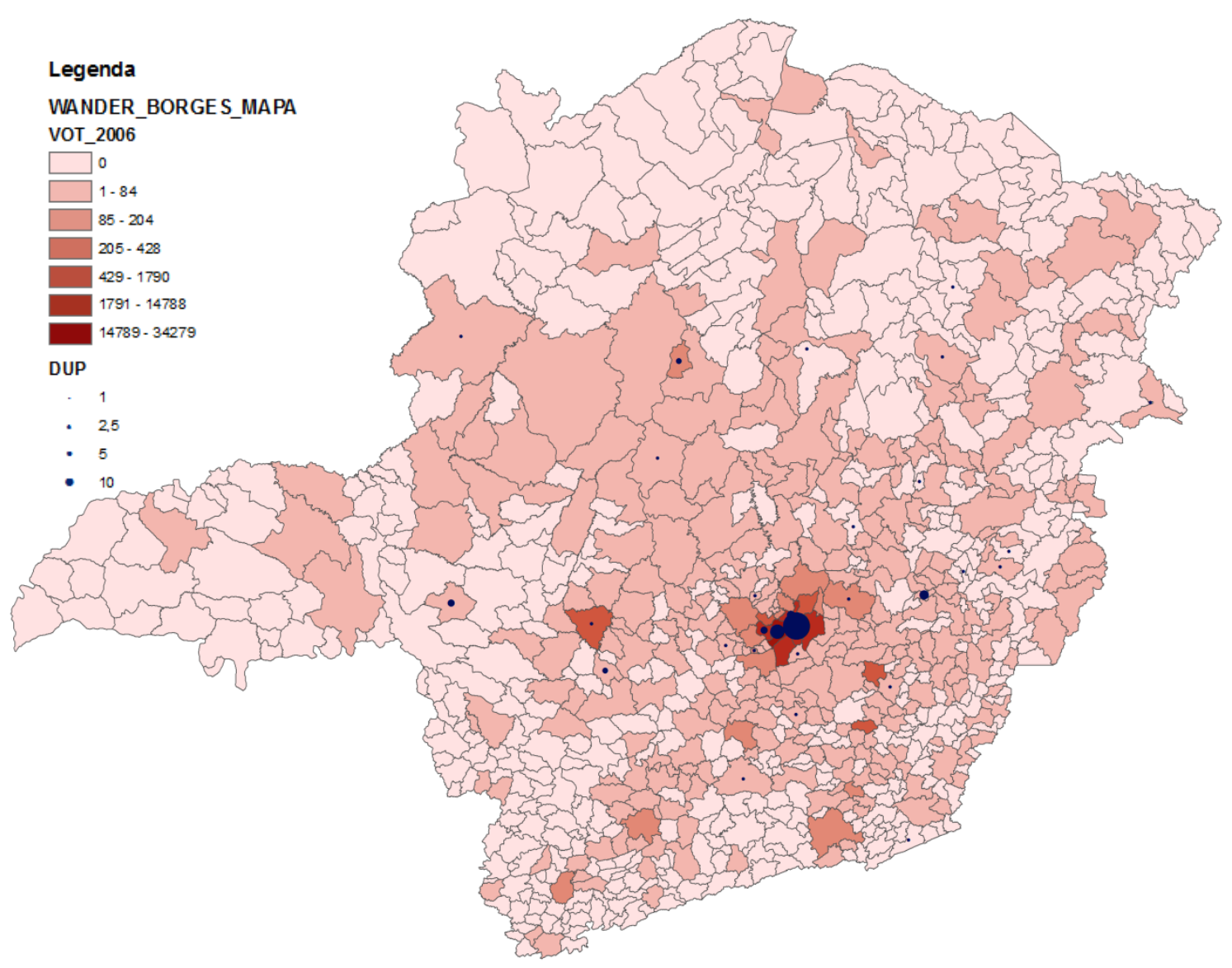

PERFIL CONCENTRADO/DOMINANTE 
MAPA 2 - DISTRIBUIÇÃO VOTAÇÃO ELEIÇÃO 2006 E LEIS DUP APRESENTADAS (08) / DEP. ESTADUAL CHICO UE.IO

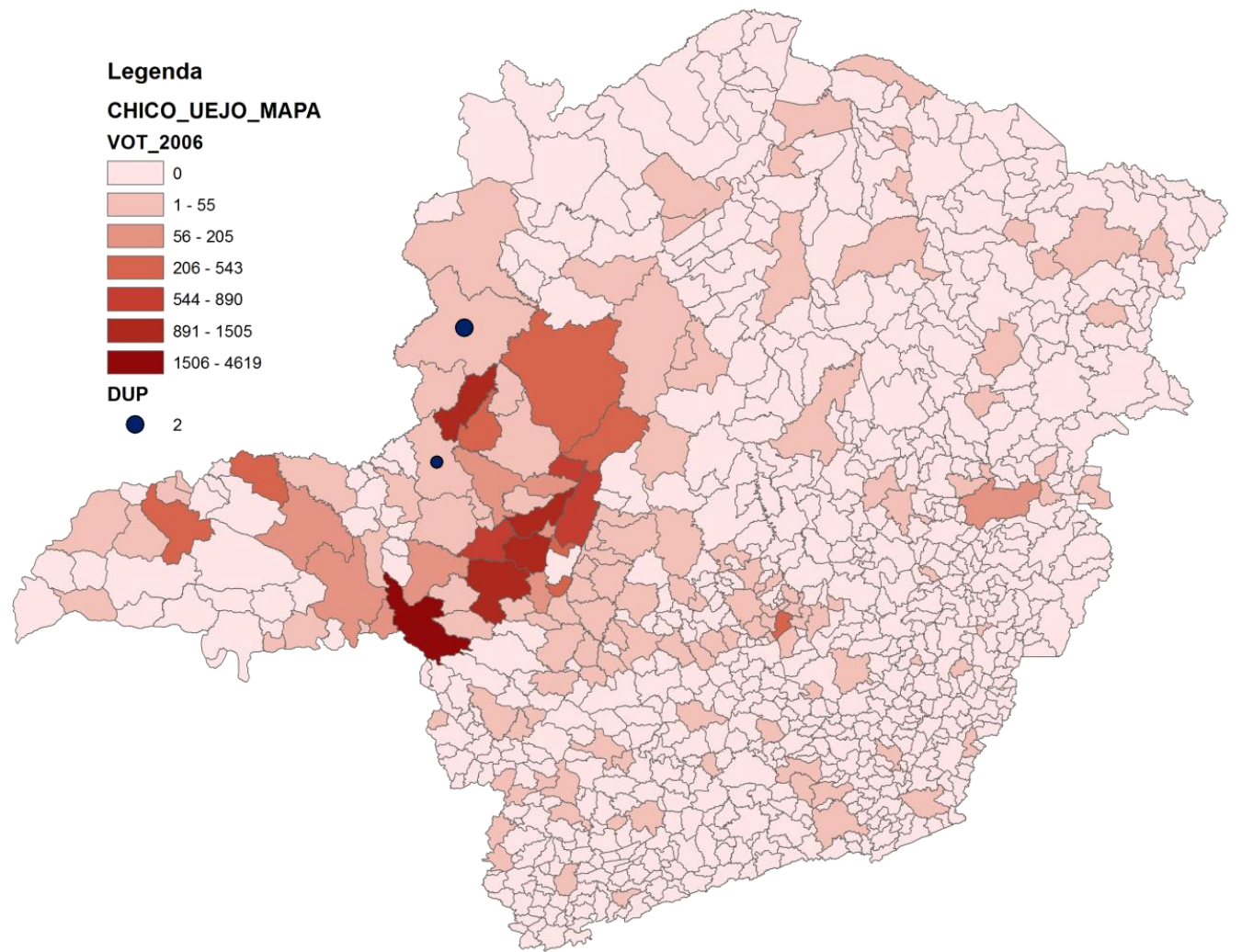




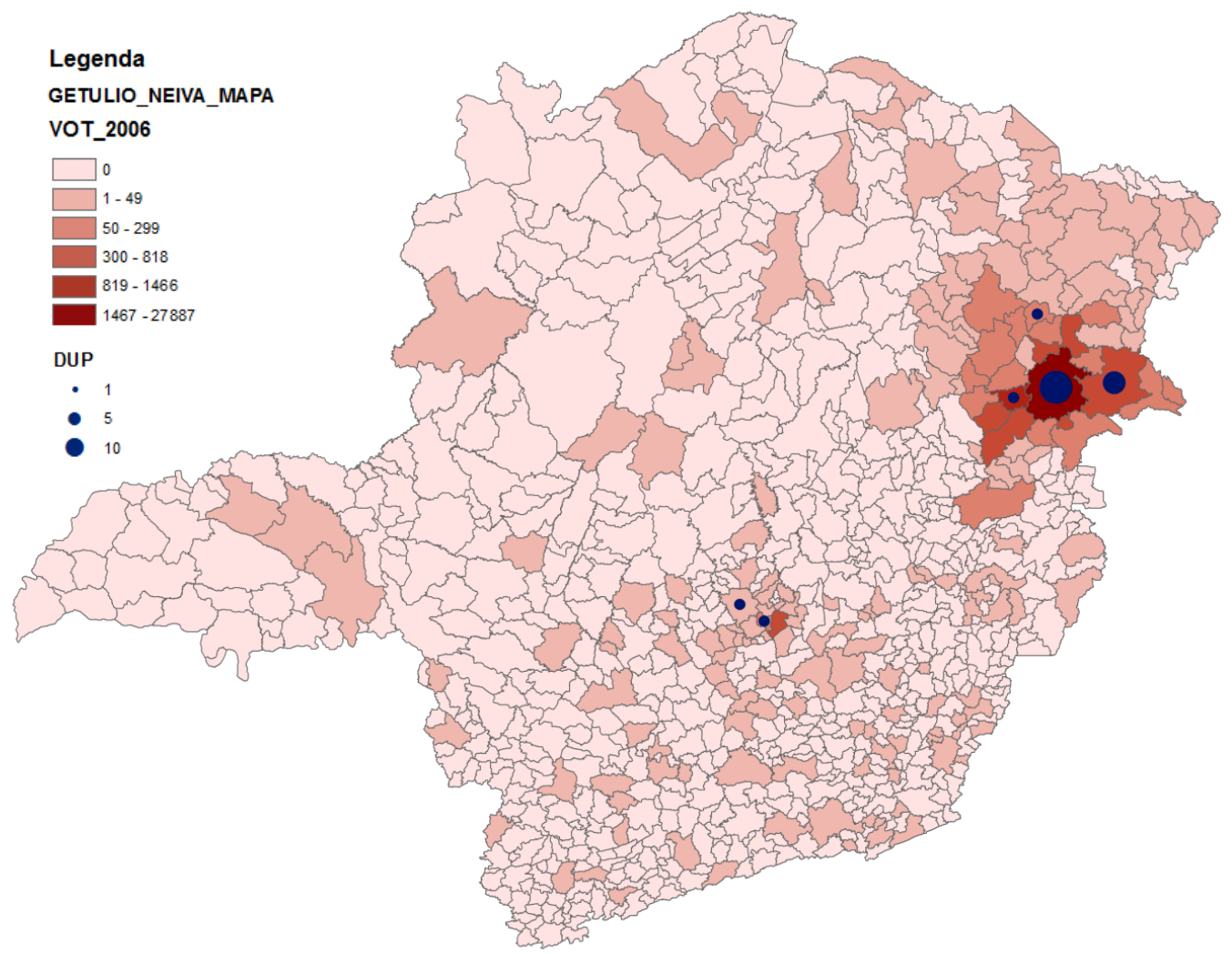

PERFIL CONCENTRADO/ NÃO DOMINANTE

MAPA 4 - DISTRIBUIÇÃO VOTAÇÃO ELEIÇÃO 2006 E LEIS DUP APRESENTADAS (75) / DEP. ESTADUAL LUIZ HUMBERTO CARNEIRO

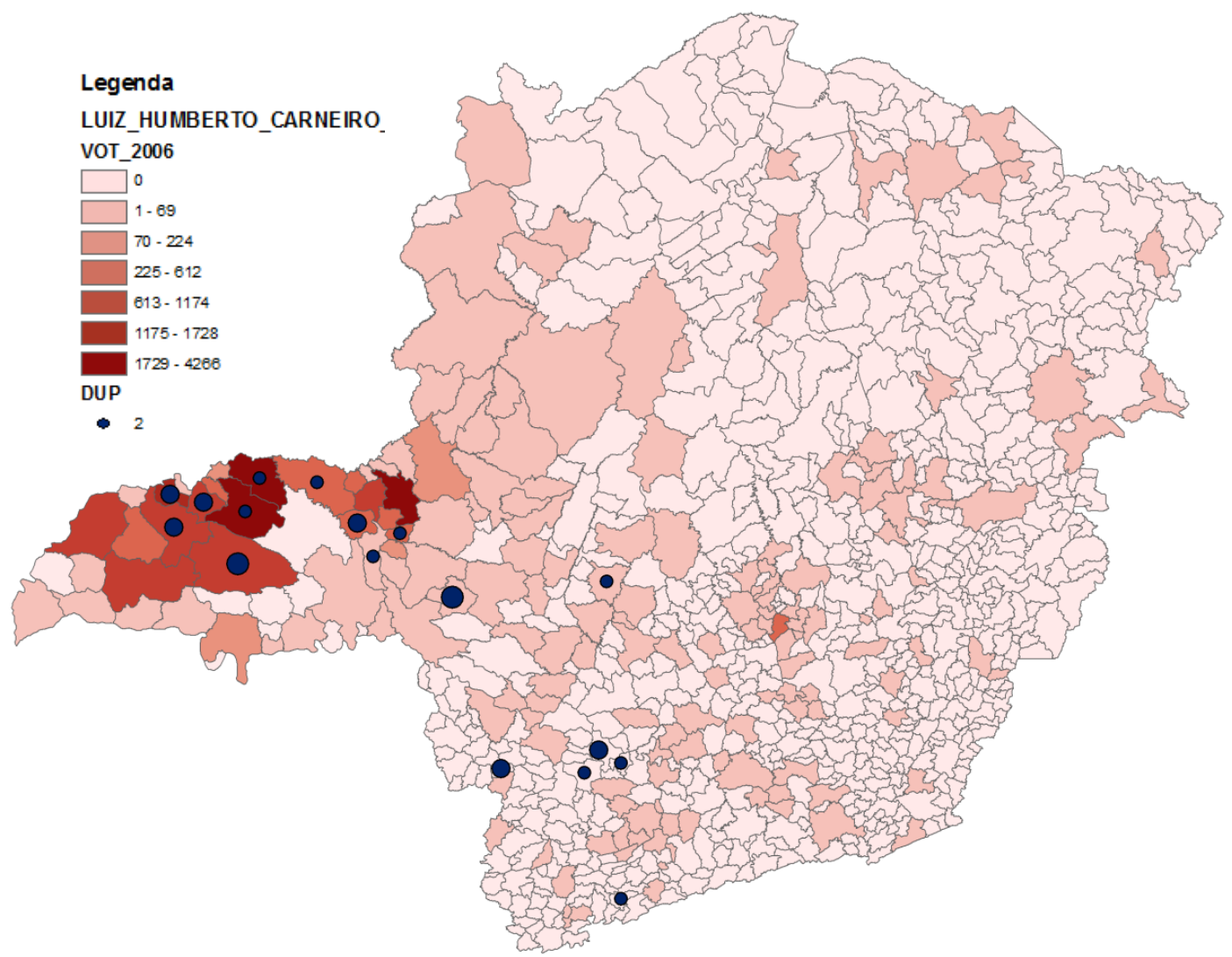




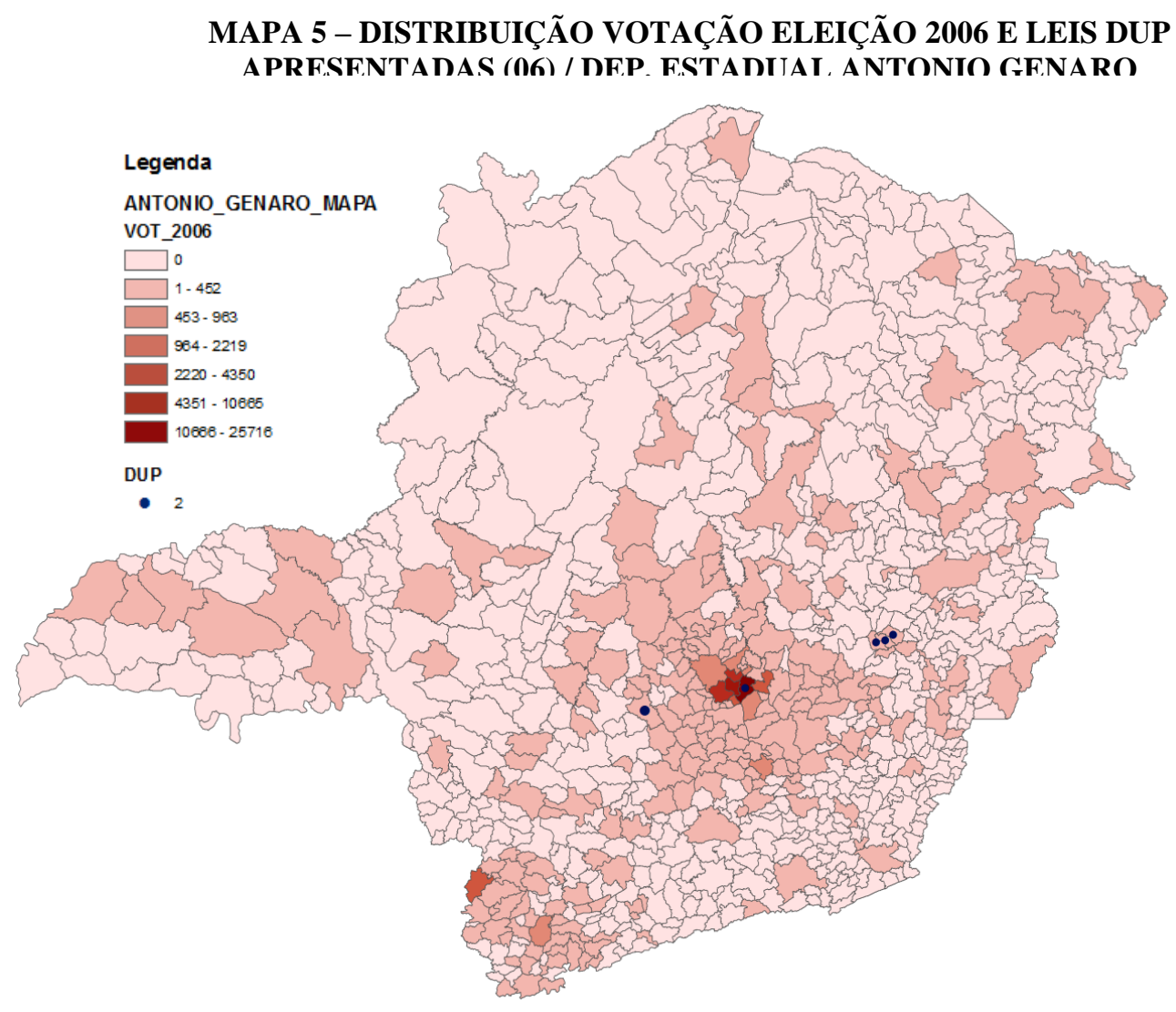

MAPA 6 - DISTRIBUIÇÃO VOTAÇÃO ELEIÇÃO 2006E LEIS DUP APRESENTADAS (24) / DEP. ESTADUAL TENENTE LÚCIO

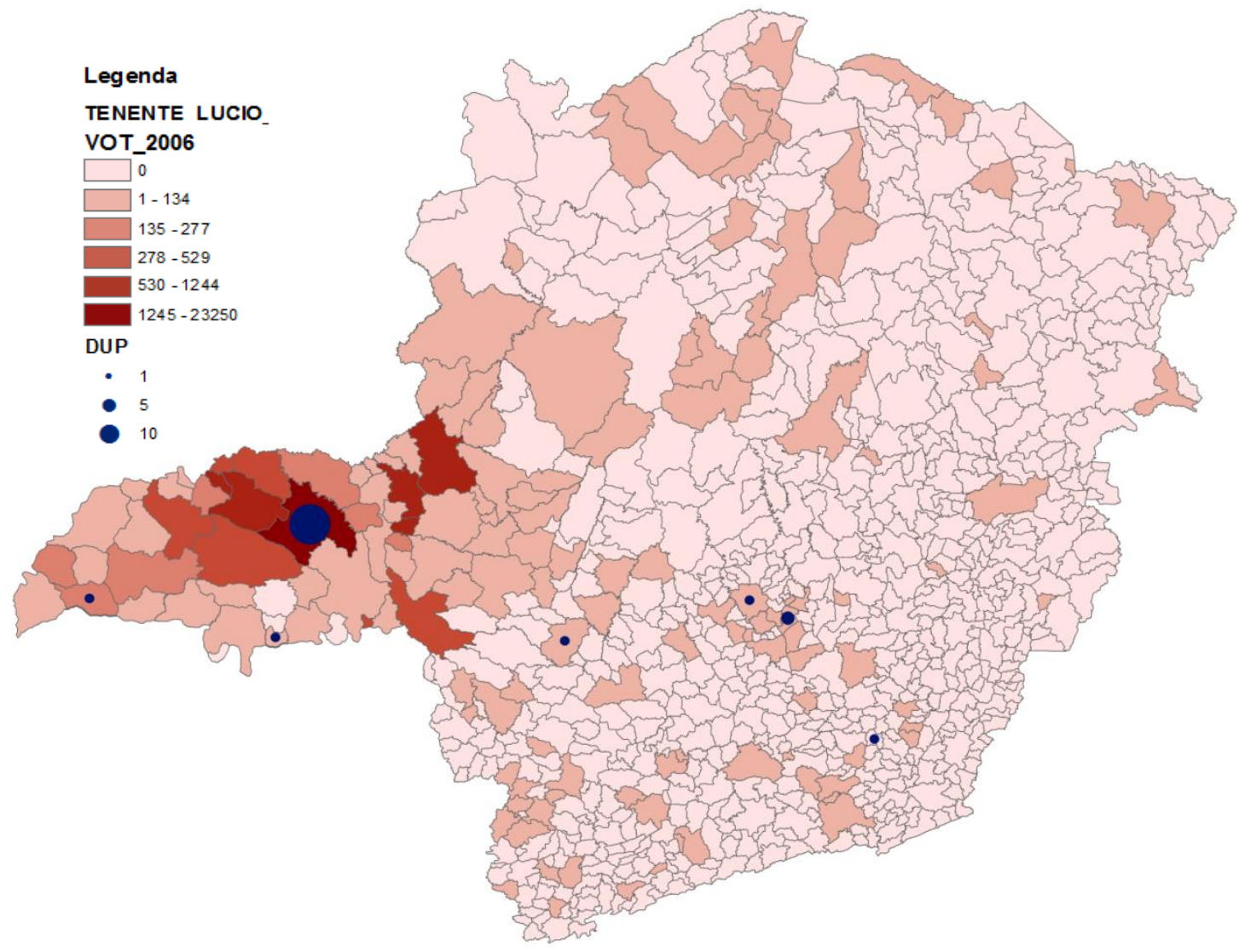




\section{PERFIL DISPERSO /DOMINANTE}

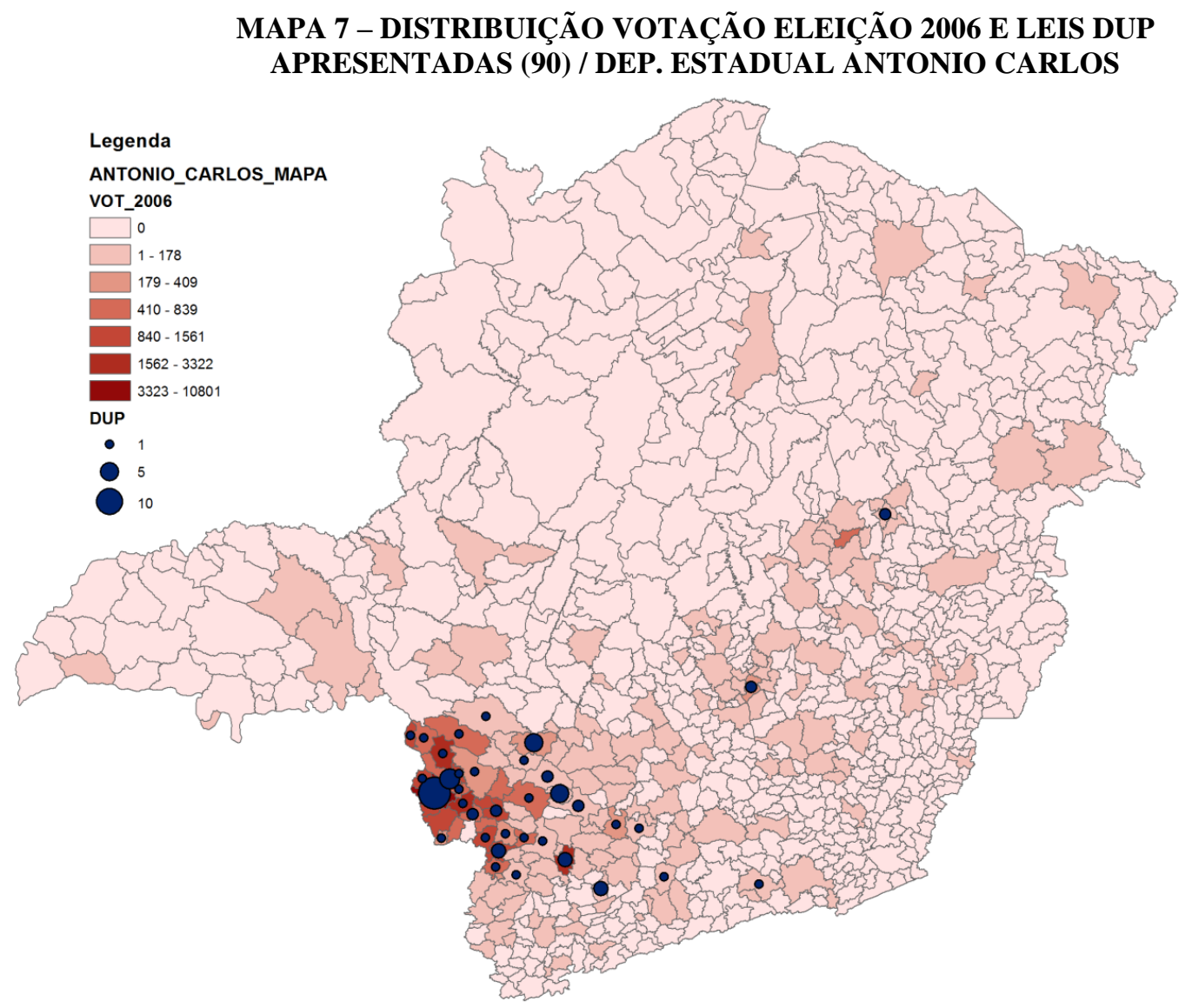

MAPA 8 - DISTRIBUIÇÃO VOTAÇÃO ELEIÇÃO 2006 E LEIS DUP APRESENTADAS (03) / DEP. ESTADUAL REMOLO ALOISE

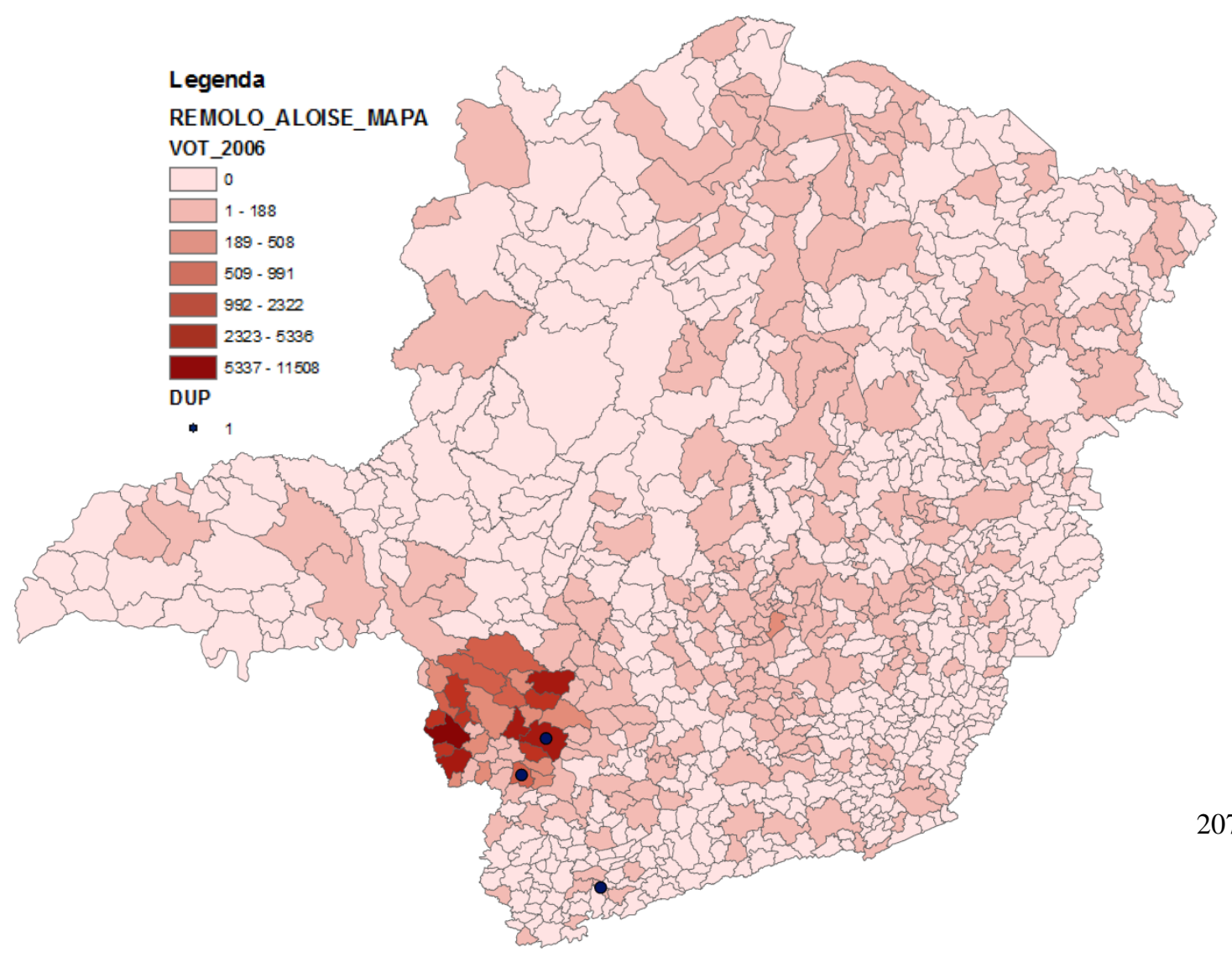


MAPA 9 - DISTRIBUIÇÃO VOTAÇÃO ELEIÇÃO 2006E LEIS DUP APRESENTADAS (25) / DEP. ESTADUAL MAURI TORRES

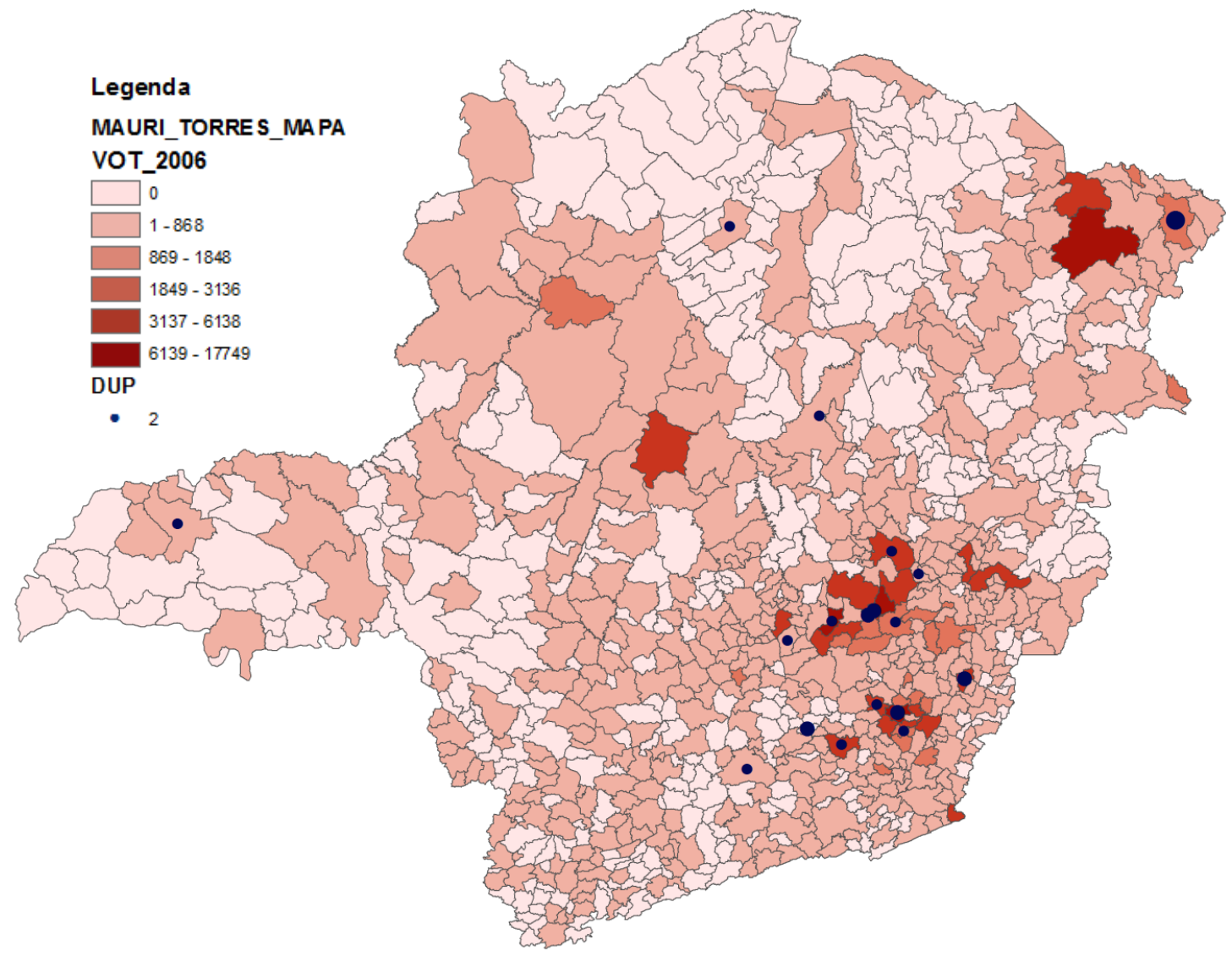

PERFIL DISPERSO / NÃO DOMINANTE 


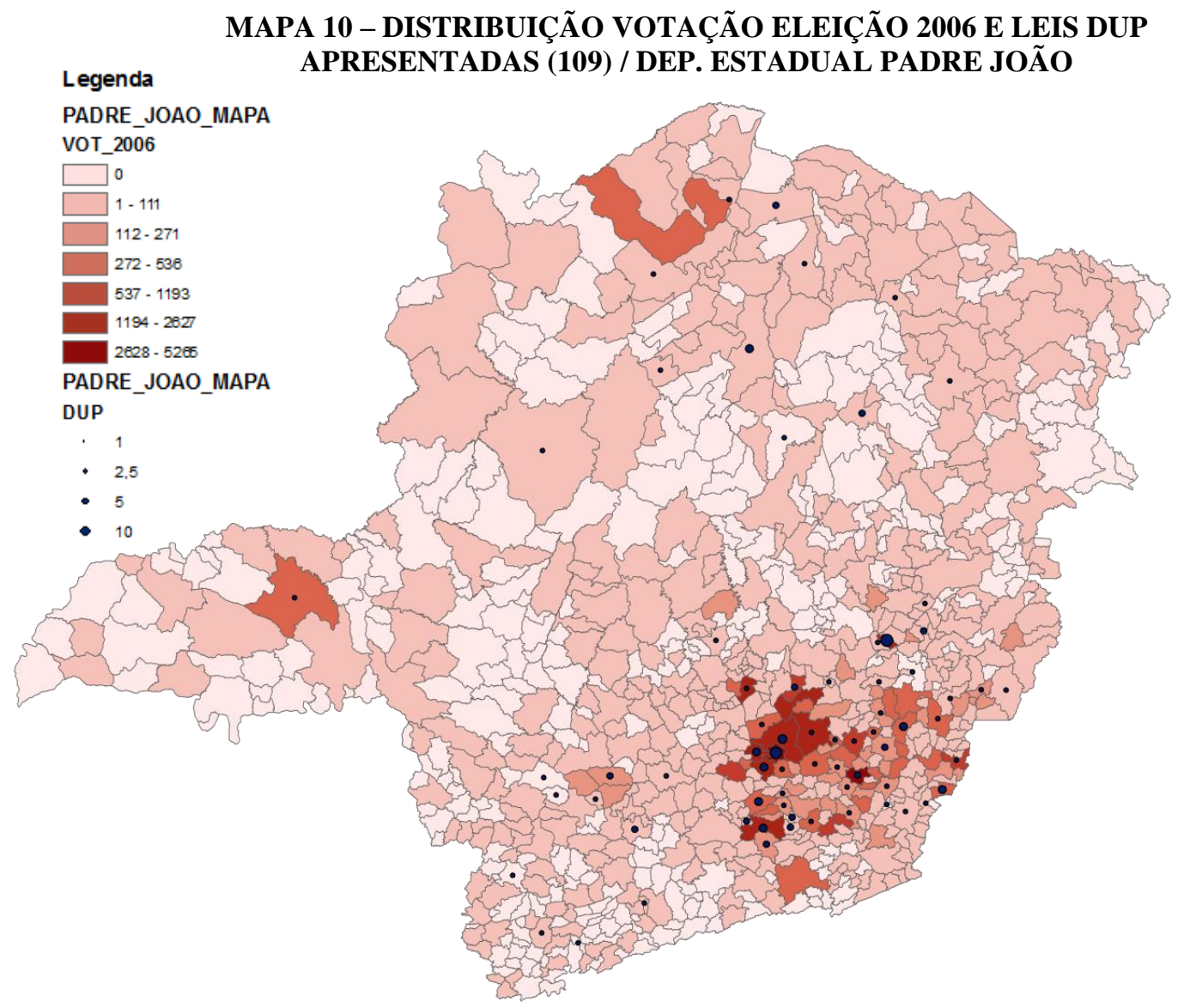

MAPA 11 - DISTRIBUIÇÃO VOTAÇÃO ELEIÇÃO 2006 E LEIS DUP APRESENTADAS (02) / DEP. ESTADUAL MARCUS PESTANA

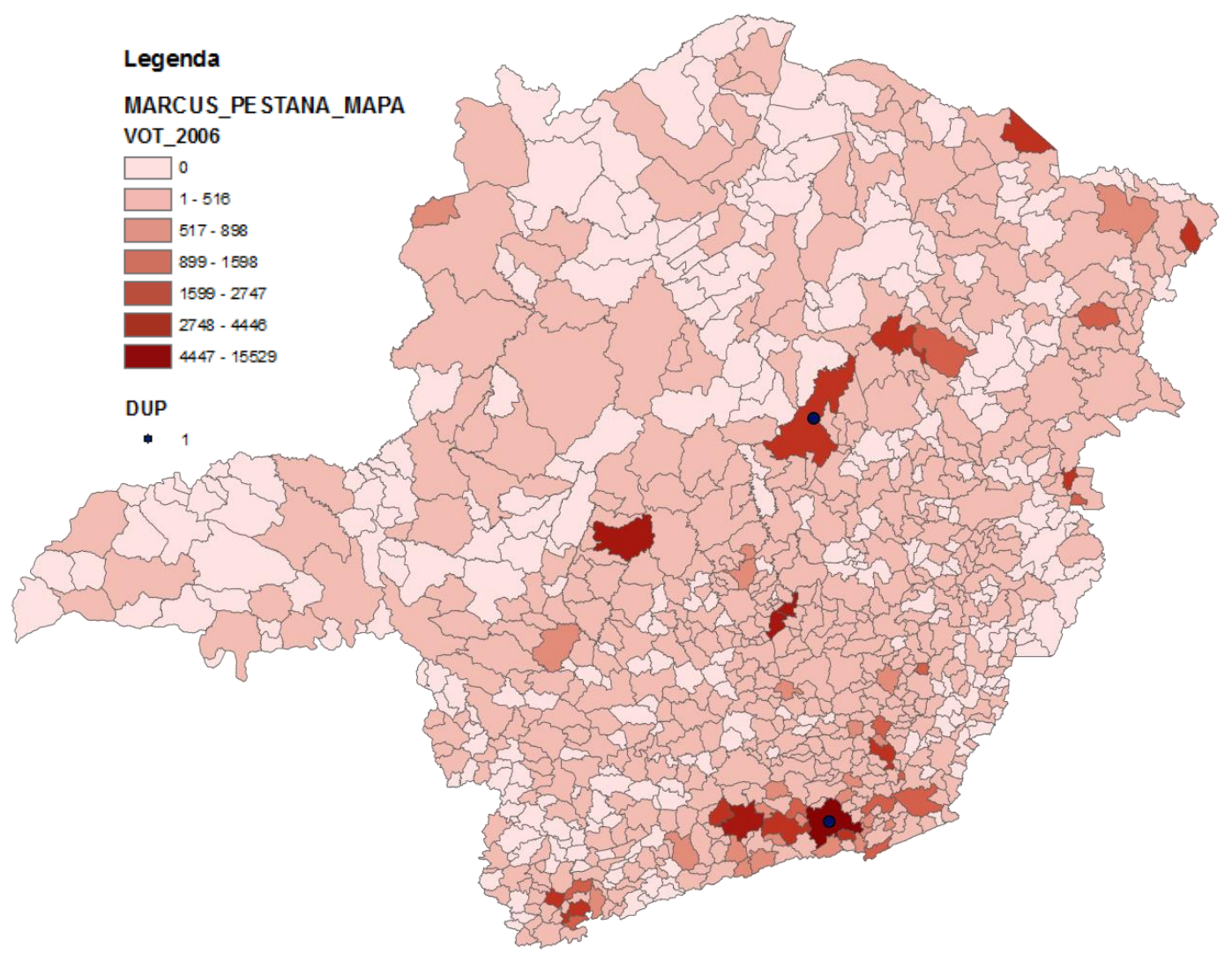




\section{MAPA 12 - DISTRIBUIÇÃO VOTAÇÃO ELEIÇÃO 2006E LEIS DUP APRESENTADAS (21) / DEP. ESTADUAL ZEZÉ PERRELLA}

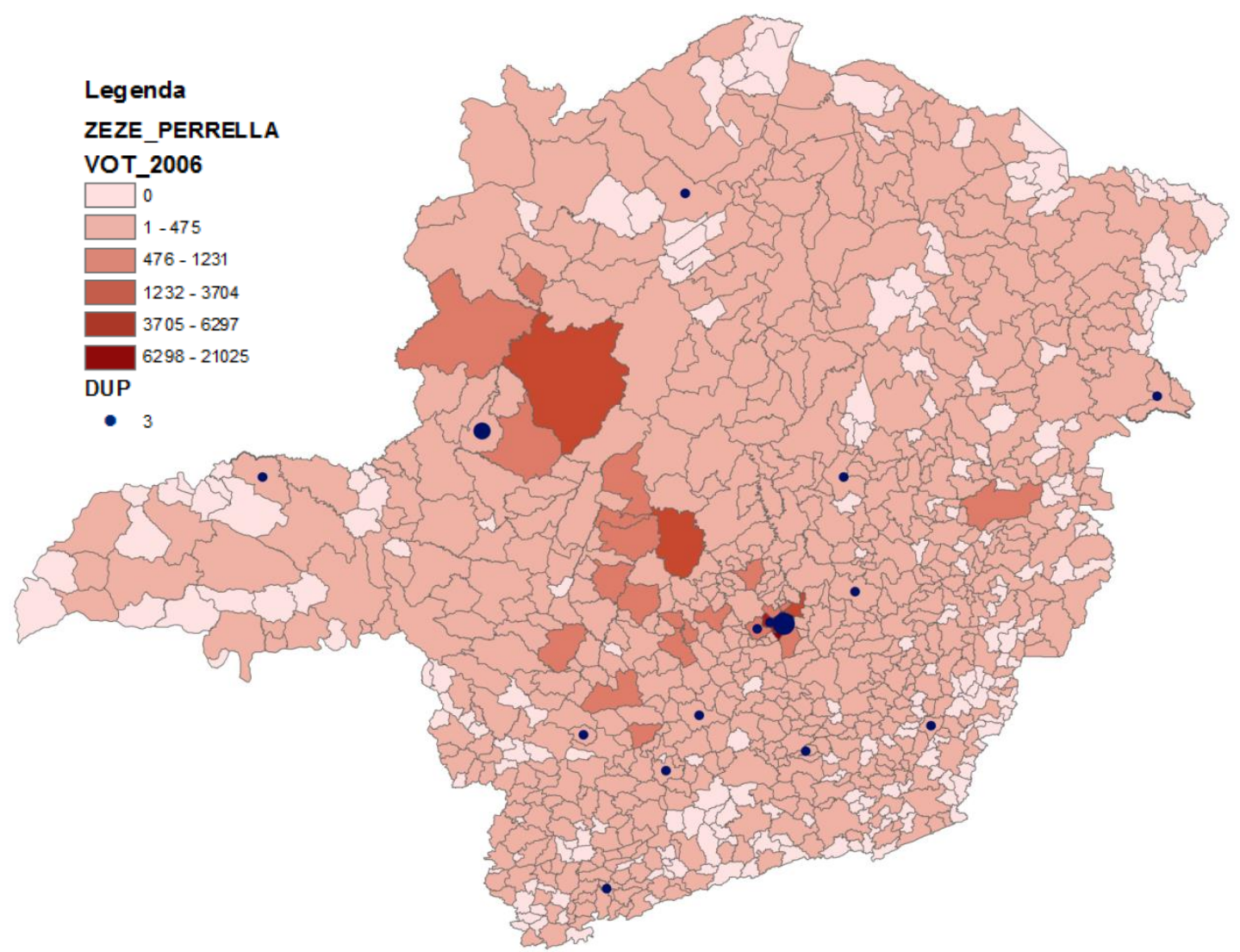

Os mapas dos doze deputados selecionados indicam que as proposições de LDUP são destinadas, em boa medida, às entidades de municípios nos quais os deputados obtiveram votação. Na maioria dos casos, as LDUP estão concentradas em municípios onde o deputado obteve maior parte de sua votação. Além disso, os mapas evidenciam que a utilização das LDUP como mecanismo de conexão independe do perfil de votação do deputado. Como já explicitado anteriormente, na legislatura analisada (2007-2011), praticamente todos os parlamentares que exerceram mandato propuseram Leis de Declaração de Utilidade Pública. No entanto, há considerável variação na proposição dessa matéria. Diante desse cenário, quais os fatores estariam relacionados com a variação do uso desse mecanismo de conexão eleitoral? 
Gráfico 3: Distribuição da Variável Dependente - Frequência da apresentação de Leis de declaração de Utilidade Pública

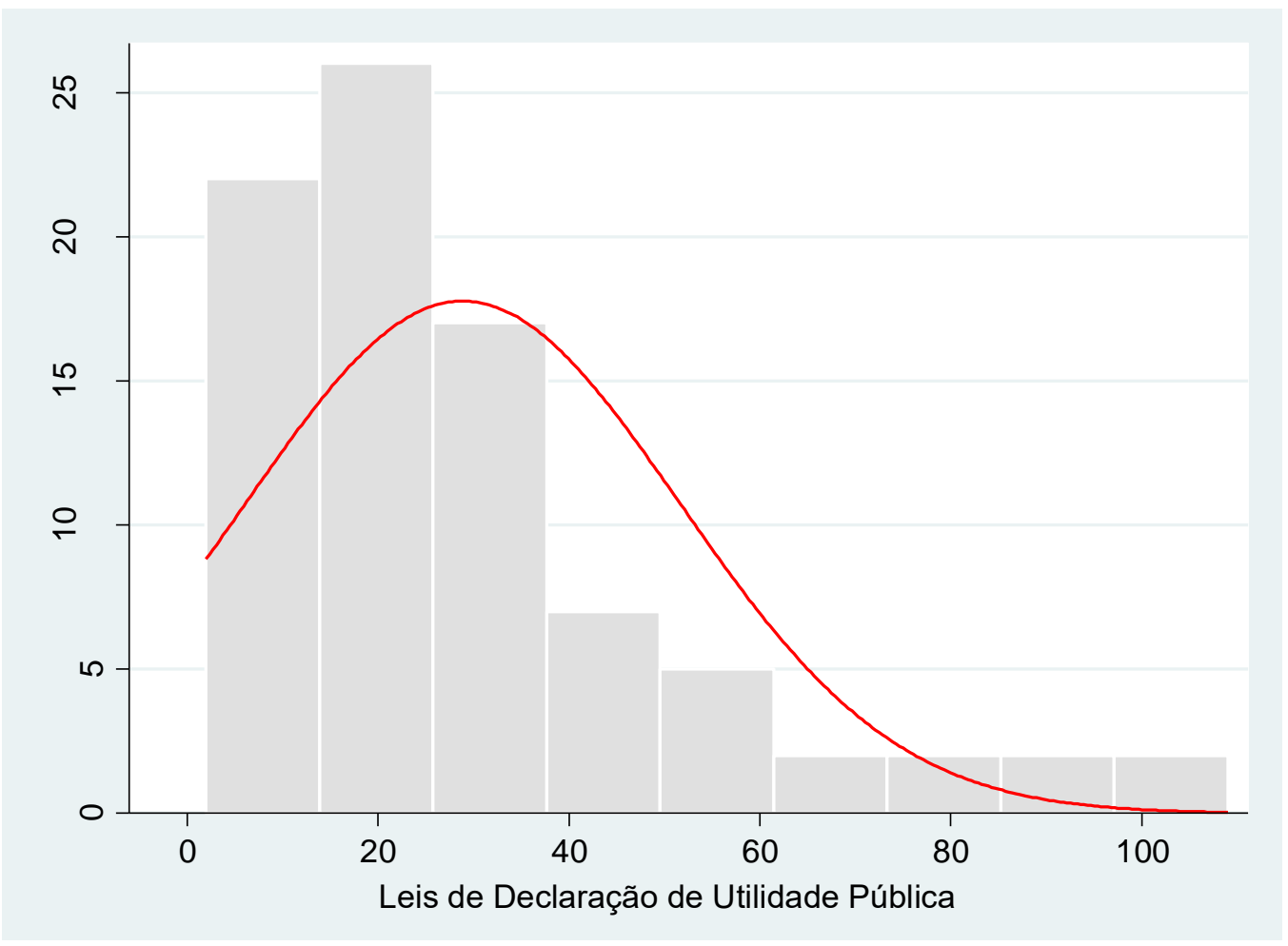

O gráfico 3 apresenta a distribuição da frequência com que os parlamentares apresentaram Leis de Utilidade pública na ALMG entre 2007 e 2011. A média do número de proposições por deputado é de 29 , com um desvio padrão de 22 , 6, mínimo de 2 Leis propostas e máximo de 109. O ajuste dos dados à curva normal nos ajuda a visualizar o padrão negativo de assimetria dos dados. Isso significa dizer que a maior parte dos parlamentares apresentou menos de 40 LDUP. Significa também que a regressão de tais dados exige um modelo que leve em consideração as implicações decorrentes de uma distribuição assimétrica.

Os modelos tradicionais de regressão $\operatorname{OLS}^{14}$ assumem que a variável dependente - a variável resposta que será regredida - é continua e normalmente distribuída. No entanto, algumas categorias analíticas se enquadram no grupo de eventos raros, o que implica na observância predominante de pequenos valores no conjunto de dados coletados.Uma alternativa seria a utilização do modelo de contagem clássico de

\footnotetext{
${ }^{14}$ Ordinary Least Square. A tradução aceita para o português é Mínimos Quadrados Ordinários. O nome se refere ao objetivo básico desse modelo que é: a partir do resultado da média das médias preditas das variáveis, ceteris paribus, estimar o impacto (positivo ou negativo ) das variáveis independentes sobre um variável dependente que mensura o fenômeno estudado.
} 
Poisson, no entanto,o pressuposto de que a média condicional e a variância da distribuição são iguais é violada pela maior parte dos dados nas ciências sociais. No nosso caso específico, como pode ser visto no gráfico 3, não é possível assumir que a incidência de proposições de LDUP é constante no tempo. Assim, utilizaremos um ajuste derivado da família dos modelos de Poisson e que assumi a distribuição de Pascal, a saber, o modelo binomial negativo descrito na notação abaixo.

$$
f(k ; r, p)=\operatorname{Pr}(X=k)=\left(\frac{k+r-1}{k}\right) p^{k}(1-p)^{2}
$$

A partir da distribuição binomial, o modelo estima a probabilidade de ocorrência de falha (ocorrência) do evento estudado $(\operatorname{Pr}(X=k))$. Ou seja, estima o quanto cada variável controlada no modelo $\left(p^{k}(1-p)\right)$ contribui para a ocorrência de um determinado evento, no nosso caso, a proposição de Leis de Declaração de Utilidade Pública.

Análises anteriores acerca do padrão de atuação dos legisladores brasileiros podem nos indicar pistas de possíveis fatores relacionados a incidência de proposições de LDUP. Assim, a partir de hipóteses derivadas da literatura, testaremos o efeito das seguintes variáveis sobre a incidência da proposição de LDUP:

$$
\gamma=\alpha+\beta_{1}+\beta_{2}+\beta_{3}+\beta_{4}+\beta_{5}+\beta_{6}+\varepsilon
$$

$\beta_{1}$ Índice de Concentração - O padrão de votação concentrado foi apontado por Barry Ames (2003) como um dos padrões típicos dos deputados federais no Brasil. Nesta dimensão pode ser enquadrado o parlamentar cujo a votação concentra-se em um (ou poucos) reduto eleitoral, sendo, portanto, esperado que esse parlamentar mantenha uma forte vinculação com os eleitores dessa região. Sendo assim, os deputados estaduais da ALMG com um padrão de voto concentrado devem apresentar maior número de proposições de LDUP. 
H1: Deputados estaduais com padrão de votação concentrado apresentam maior número de Leis de Utilidade Pública.

$\beta_{2}$ Índice de Dominância - Outra dimensão relacionada ao padrão de votação proposta por Ames (2003) qualifica o parlamentar como dominante em determinado distrito eleitoral. O prestígio pessoal e a alta legitimidade perante os eleitores de determinado distrito eleitoral, cooperam para a diminuição da competição e torna o parlamentar o único candidato viável daquele reduto eleitoral. Assim como no caso da dimensão da concentração, deputados estaduais da ALMG com um padrão de votação dominante devem apresentar maior número de proposições.

H2: Deputados estaduais com padrão de votação dominante apresentam maior número de Leis de utilidade Pública.

$\beta_{3}$ Posicionamento Ideológico -o controle dessa variável parte do pressuposto que o posicionamento ideológico pode ser considerado um bom preditor do comportamento dos atores políticos (BOBBIO, 2003), bem como do comportamento dos parlamentares (MELO E SANTOS, 2012). Dado que a atuação dos partidos conservadores no Brasil tem sido ligada a um comportamento de natureza clientelista (MAINWARING, et al, 2000), espera-se que os parlamentares de partidos posicionados mais à esquerda do espectro ideológico proponham menos LDUP.

H3: Deputados estaduais posicionados à esquerda no espectro ideológico apresentam menor quantidade Leis de Utilidade Pública.

$\beta_{4}$ Clivagem Governo x Oposição - em detrimento do posicionamento ideológico dos partidos dos parlamentares, alguns analistas como Zucco (2009) argumentam que, para o caso do congresso nacional, a clivagem governo oposição é um melhor preditor do comportamento parlamentar. Uma vez que os parlamentares participantes da base governista possuem mais acesso a recursos e possibilidade de ocupar cargos de liderança e, dado que as LDUP são aprovados terminantemente nas comissões, esperamos que esses deputados proponham mais LDUP. 
H4: Deputados estaduais que ocupam cargos de liderança na assembleia apresentam maior quantidade de Leis de utilidade Pública.

$\beta_{5}$ Regiões Metropolitanas x Interior - na análise desenvolvida por Carvalho (2003) acerca do padrão de votação dos parlamentares brasileiros, é testada a hipótese de que parlamentares de regiões metropolitanas possuem um padrão de atuação diferente dos parlamentares que possuem domicílio eleitoral nas cidades interioranas. A pressuposição é que a magnitude dos distritos nas áreas metropolitanas e a dificuldade de se tornar um candidato dominante no que diz respeito ao padrão de votação, conduz os deputados a um comportamento parlamentar menos localista, optando por uma atuação pautada por intervenções gerais, como discursos e projetos de Lei de amplo espectro. Assim, no caso dos parlamentares da ALMG, esperamos que os deputados com domicílio eleitoral na área metropolitana proponham menos LDUP.

H5: Deputados estaduais com domicílio eleitoral em áreas metropolitanas apresentam menor quantidade de Leis de Utilidade Pública.

$\beta_{6}$ Emendas Parlamentares - análise da política orçamentária do sistema político brasileiro sugere que as emendas parlamentares são um importante instrumento de coordenação política (FIGUEIREDO E LIMONGI,2008). Além disso, as emendas parlamentares possuem efeitos positivos sobre os indicadores sociais nas municipalidades brasileiras (RENNÓ; PEREIRA, 2013). As características do sistema político brasileiro tornam as emendas parlamentares ao orçamento um importante instrumento de vinculação entre os deputados e seus eleitores, seja no nível nacional, seja no plano subnacional. Dessa forma, assumindo que a proposição de Leis de Declaração de Utilidade Pública e as Emendas Parlamentares fazem parte de um mesmo pacote de atuação particularista, esperamos que os deputados que enviam emendas parlamentares proponham mais LDUP.

H6: A incidência de proposição de Leis de Utilidade pública varia em função do uso de emendas parlamentares como instrumento de conexão eleitoral. 
A hipótese H6 é derivada de um modelo de comportamento racional dos parlamentares assumido a priori e sedimentado em quatros pressupostos da ação individual dos atores:

1.Dentro de certos limites, o ator tem consciência de suas preferências e é capaz de maximizá-las a partir de metas e estratégias (ELSTER, 1989);

2. A escolha das estratégias de maximização varia em função do horizonte de alternativas, finitas e fixas, à disposição do agente maximizador (idem, 1989);

3. O cálculo de ação dos atores leva em consideração o timing dos benefícios recebidos e os custos da estratégia empregada. A expectativa dos ganhos deve superar o custo da ação de maximização (RIKER, 1990);

4. É provável que, em decorrência do terceiro pressuposto, a incerteza derivada da relação entre custos e benefícios influencie a escolha da estratégia dos atores (PRZEWORSKI, 1988, KNIGHT, 1992).

O arranjo institucional brasileiro limita o horizonte de alternativas (finitas e fixas) do legislador subnacional, conduzindo-o ao "vale das ações de alcance limitado". Assim, posto a necessidade de encontrar estratégias válidas, de custo limitado e alta expectativa de benefícios, é esperado que os deputados congreguem em seu pacote de atuação parlamentar todas as estratégias que viabilizem seu sucesso eleitoral.

\section{Quadro 1: Sinal esperado das variáveis independentes}

\begin{tabular}{lc}
\hline Variáveis Independentes & Sinal desperado da relação \\
\hline & \\
Índice de Concentração & + \\
Índice de Dominância & + \\
Posicionamento Ideológico & - \\
Governo X Oposição & + \\
Regiões Metropolitanas X Interior & - \\
Emendas Parlamentares & + \\
\hline
\end{tabular}

A tabela 4 apresenta os resultados do modelo binomial negativo estimado. $\mathrm{O}$ teste de ajuste geral do modelo (Prob>chi2) indica que todos os coeficientes estimados 
possuem média igual a zero, pressuposto básico dos ajustes dos modelos da família de Poisson. Além disso, o teste alfa (likelihood-ratiotest alpha) indica com segurança que a variância dos dados é igual à media (equidispersos). No entanto, o alto valor do teste (712.85) sugere que alfa não é zero e, portanto, o modelo binomial negativo é mais apropriado do que o modelo de Poissan, neste caso.

Optamos por estimar os coeficientes na forma de incident rate ratios. O que significa que os resultados dos coeficientes devem ser lidos como taxas de incidência das covariáveis sobre a variável dependente. Ou seja, o quanto cada variável independente aumenta a incidência da proposição de Leis de Declaração de Utilidade Pública. Uma forma intuitiva de interpretar o modelo ajustado é interpretá-lo como um teste de hipótese de cada uma das variáveis supracitadas e controladas no modelo.

Tabela 2: Determinantes da Incidência de Proposição de Leis de Declaração de Utilidade Pública ALMG (2007-2011)

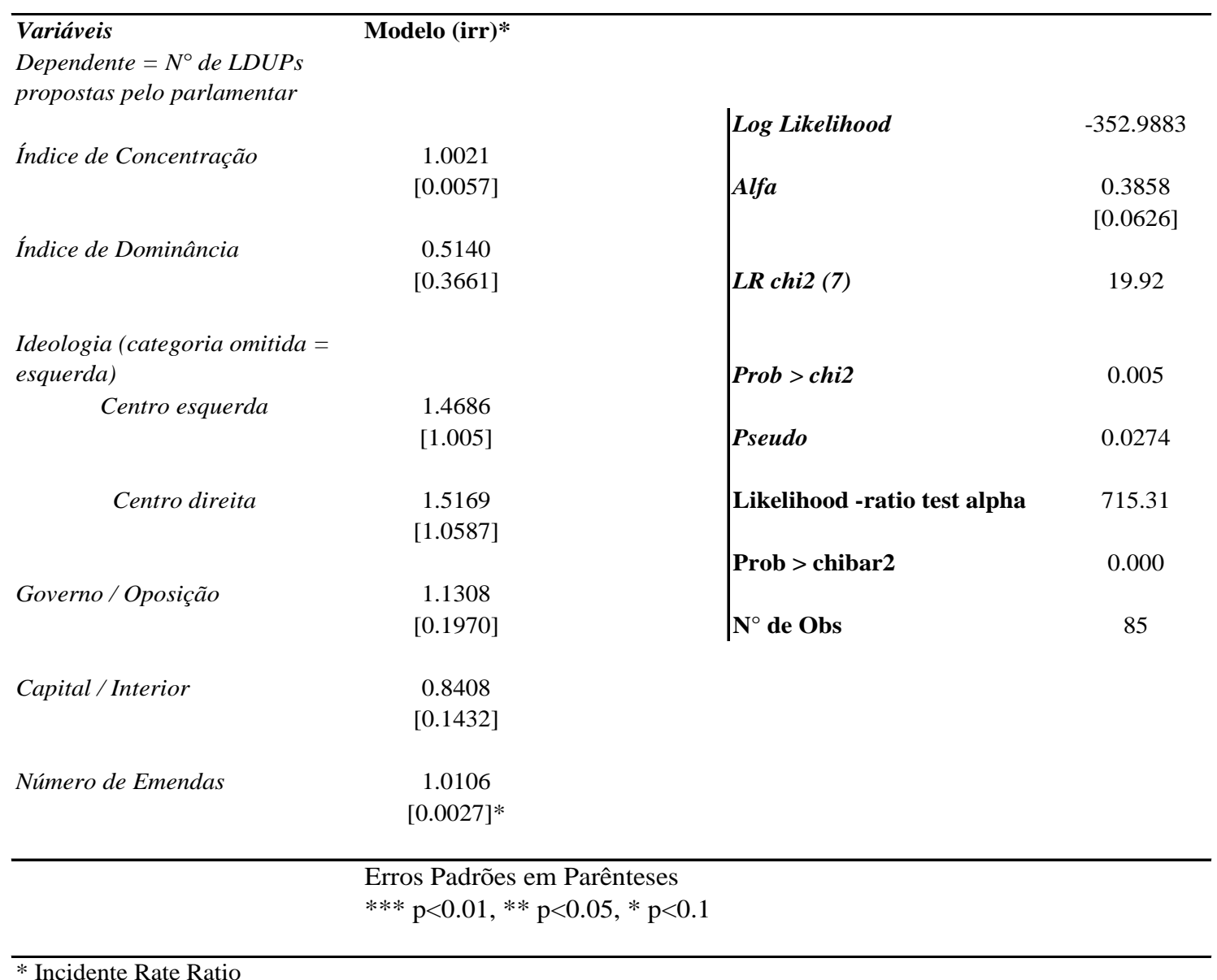


No que diz respeito às variáveis proxies do padrão de votação dos parlamentares, apesar de terem seus coeficientes na direção esperada, o índice de concentração e o índice de dominância não são estatisticamente significativos. Da mesma forma, ainda que os coeficientes indiquem que os parlamentares situados mais a direita do espectro ideológico proponham mais LDUP, esta variável também não é estatisticamente significativa. Os coeficientes das variáveis Governo/Oposição e Capital/ Interior também não apresentam significância estatística.

De acordo com as expectativas, o número de emendas parlamentares enviadas pelos deputados estaduais está relacionado com um maior número de LDUP. No modelo ajustado, o fato de o parlamentar ter enviado emendas para a sua base eleitoral aumenta em mais de uma vez ${ }^{15}$ (1.0106) a incidência de proposição de Leis de Declaração de utilidade Pública. Nós argumentamos que as duas ações dos parlamentares compõe um pacote de atuação particularista. Assim, os deputados que se enquadram em uma dessas medidas, naturalmente, encaixam-se também na outra. Os deputados estaduais que se enquadram no modelo distributivista de comportamento parlamentar, tenderão a adotar o máximo de medidas geograficamente delimitadas a fim de maximizar seus ganhos eleitorais.

Assumindo que o maior objetivo dos parlamentares é conseguir a reeleição- ou o sucesso eleitoral e outros cargos representativos - e que os deputados subnacionais tem seu universos de prerrogativas muito limitado, não causa espanto que duas medidas de natureza geograficamente localizadas estejam intrinsecamente e estatisticamente relacionadas. Em outros termos, o fato das outras variáveis não serem estatisticamente significativas contribui para o principal argumento invocado neste trabalho para justificar a proposições de LDUP, a saber, o de que o modelo federativo brasileiro combinado ao baixo custo desse tipo de proposição e a expectativa de retornos eleitorais, conduz os parlamentares a uma via particularista de atuação.

Não obstante o fato dos estados constituírem-se em subsistemas eleitorais (LIMA JR, 1997), análises da atividade parlamentar no plano nacional têm indicado que, ao contrário de um ambiente permeado pelo segredo ineficiente ${ }^{16}$ (SHUGART E

\footnotetext{
${ }^{15}$ Ou seja, se o Parlamentar propõe em média 5LDUP, ele passa a propor, em média, 10 LDUP se o mesmo também propõe emendas ao orçamento.

16 O termo Segredo Ineficiente foi cunhado por SHUGART e CAREY (1992) com o objetivo de contrastar o cenário descrito por Gary Cox (1987) em The EfficientSecret. Em sua análise do caso inglês, Cox argumenta que a organização dos trabalhos legislativos centralizada no gabinetee a disciplina partidário verificados na câmara dos comuns (câmara baixa britânica) explicaria, a despeito dos incentivos da arena eleitoral para uma atuação particularista dos parlamentares, a produção de Leis de
} 
CAREY, 1992), a atividade legiferante dos congressistas brasileiros tem sido pautada, sobretudo, por uma lógica de abrangência nacional (AMORIM NETO E SANTOS; 2003). A impossibilidade de testar o cenário contrafactual inviabiliza inferir que, se expostos aos mesmos constrangimentos e alternativas, os parlamentares subnacionais reproduziriam o mesmo comportamento encontrado pelos referidos autores. No entanto, assumir o argumento simplista de que parlamentares, sob qualquer circunstância, preferem um comportamento distributivista, nos parece um caminho pouco profícuo e de limitado potencial analítico.

\section{Considerações Finais}

O fato da variação do número de Leis de Declaração de Utilidade Pública não poder ser explicado por nenhum dos outros fatores controlados - proxies produzidas à luz dos argumentos apresentados pela literatura - indica que devemos relativizar a força desse mecanismo vis à vis a proposição de emendas ao orçamento. Isso não significa que a proposição de LDUP deva ser desconsiderada enquanto mecanismo de conexão eleitoral, mas que a utilização desse dispositivo está diretamente relacionada com o baixo custo de sua elaboração e aprovação.

Enquanto as emendas parlamentares ao orçamento são um produto da negociação entre Executivo e Legislativo, as LDUP são resultantes de arranjos internos dos atores do poder legislativo, o que facilita a ação dos deputados e qualifica todos os parlamentares como potenciais proponentes. Assim, a despeito da pouca relevância política e legislativa desse tipo de proposição e da incerteza do retorno eleitoral que possa emergir dessa relação entre parlamentar e sua base eleitoral, qual justificativa racional pode ser apresentada para que os deputados não utilizem esse mecanismo de conexão eleitoral?

Vale ressaltar ainda que elencar mecanismos particularistas de ação dos parlamentares não significa afirmar que todos deputados são pautados por esse tipo de agenda e, mais do que isso, não significa dizer que este é o único modelo de atuação dos parlamentares da ALMG. No entanto, ainda que os parlamentares queiram se dedicar a

caráter nacional. Assim, o segredo ineficente seria justamente o seu contrário. Um contexto onde duas soberanias conviveriam (Os poderes Legislativo e Executivo são escolhido através de sufrágios diferentes), aumentariam o risco de impasses e , portanto, promoveria a instabilidade. Além disso, os partidos indisciplinados,o sistema eleitoral de PR e de lista aberta favoreceria o personalismo e o paroquialismo. 
produção de normas gerais, é razoável presumir que o esvaziamento da agenda subnacional induza fortemente os deputados a adoção de medidas de caráter local.

Quando analisadas sob uma perspectiva comparada, as assembleias brasileiras podem ser posicionadas em diferentes níveis de institucionalização, profissionalização e padrões de comportamento legislativo (SANTOS, 2001). No caso específico da ALMG, a adoção de mecanismos de interlocução com os cidadãos, o estabelecimento de seminários legislativos e fóruns técnicos, bem como a criação da Comissãode Participação Popular e a capacitação do Staff encarregado de dar suporte a atuação parlamentar,testificam o processo de desenvolvimento institucional no qual a assembleia mineira tem experimentado nas últimas décadas (ANASTASIA, 2009). A primeira vista pode parecer contra-intuitivo que um parlamento de elevado desenvolvimento institucional tenha, ao mesmo tempo, parlamentares com grande inclinação à praticas distributivistas. No entanto, se a premissa de que a escolha das estratégias de maximização dos atores varia em função do horizonte de alternativas for aceita como verdadeira, nos parece muito menos razoável esperar que parlamentares compelidos por dispositivos constitucionais inibidores de uma prática legislativa abrangente, consigam se afastar do atrativo mercado dos benefícios geograficamente localizados. 


\section{Referências}

AMES, B. Os entraves da democracia no Brasil. Rio de Janeiro: FVG Editora, 2003. $409 \mathrm{p}$.

ANASTASIA, F. Desenvolvimento Institucional e Representação Democrática na ALMG. In: OLIVEIRA, M. C. (Org.). Assembleia de Minas e a construção coletiva de políticas públicas: eventos institucionais, 1990-2009. Belo Horizonte: Assembleia Legislativa do Estado de Minas Gerais, 2009. p. 47-54.

ARRETCHE, M. Federalismo e políticas sociais no Brasil: problemas de coordenação e autonomia. São Paulo em Perspectiva (Impresso), São Paulo, v. 18, n.2, p. 17-26, 2004.

ARRETCHE, M. Quando instituições federativas fortalecem o governo central?. Novos Estudos CEBRAP, São Paulo, n. 95, p. 39-57, Mar. 2013. Disponível em $<$ http://www.scielo.br/scielo.php?script=sci_arttext\&pid=S0101-

$33002013000100003 \& \operatorname{lng}=$ en\&nrm=iso>. acesso em 16 Nov. 2017.

ARRETCHE, M. Federalismo e igualdade territorial: uma contradição em termos?. Dados, Rio de Janeiro, v. 53, n. 3, p. 587-620, 2010. Disponível em <http://www.scielo.br/scielo.php?script=sci_arttext\&pid=S001152582010000300003\&lng=en\&nrm=iso>. acesso em 16 Nov. 2017.

BRASIL. Constituição da República Federativa do Brasil. Brasília: Senado Federal, 2001.

BOBBIO, N. Direita e Esquerda: razões e significados de uma distinção política. São Paulo: Editora da UNESP, 1995. 129 p.

CARVALHO, N. R. E no início eram as Bases: geografia política do voto e comportamento legislativo no Brasil. Rio de Janeiro: Editora Revan, 2003. 224 p.

COX, G. W. The Efficient Secret: The Cabinet and the Development of Political Parties in Victorian England. New York: Cambridge University Press, 1987. 208 p.

COX, G. e McCUBBINS, M. D. Legislative Leviatan: Party Government in the House. Berkeley: University of California Press, 1993. 289 p.

ELSTER, Jon. Marxismo, funcionalismo e teoria dos jogos Argumentos em favor do individualismo metodológico. Lua Nova, São Paulo, n. 17, p. 163-204, Junho 1989. Disponível em <http://www.scielo.br/scielo.php?script=sci_arttext\&pid=S010264451989000200009\&lng=en\&nrm=iso>. acesso em 20 Nov. 2017.

FIGUEIREDO, A.; LIMONGI, F. Política Orçamentária no presidencialismo de coalizão. Rio de Janeiro: FGV Editora, 2008. 184 p.

KNIGHT, J. Institutions and Social Conflict. Cambridge: Cambridge University Press, 1992. 234 p. 
KREHBIEL, K. Information and Legislative Organization. Yale: Yale University Press, 1991. $328 \mathrm{p}$.

LAAKSO, M.; TAAGEPERA, R. Effective Number of Parties. Comparative Political Studies, v. 12, n.1, p. 3-27. April 1979.

LIMA JÚNIOR, Olavo Brasil. Instituições políticas democráticas: o segredo da legitimidade. Rio de Janeiro: J. Zahar, 1997. 143 p.

MAINWARING, S.; MENEGUELlO, R; POWER, T. Partidos Conservadores no Brasil Contemporâneo. São Paulo: Editora Paz e Terra, 2000. 107 p.

MAYHEW, D. Congress: the electoral connection. New Haven: Yale University Press, 1974. 194 p.

MELO, C. R.; SANTOS, M. L. O que informa a ideologia? Uma análise de deputados e partidos no legislativo brasileiro. In: ENCONTRO NACIONAL DA ASSOCIAÇÃO BRASILEIRA DE CIÊNCIA POLÍTICA, 8, 2012, Gramado. Resumos... Gramado: Associação Brasileira de Ciência Política, 2012.

MINAS GERAIS. Regimento Interno da Assembleia Legislativa de Minas Gerais. Belo Horizonte: Assembleia Legislativa de Minas Gerais, 2011.

MONTEIRO NETO, A. (Org.). Governos estaduais no federalismo brasileiro: capacidades e limitações governativas em debate. Brasília: Ipea, 2014. 326 p.

PEREIRA, C.; RENÓ, L. Gastos Públicos, Emendas Orçamentárias do Legislativo e Inclusão Dissipativa nos Municípios Brasileiros: 1998 a 2010. Monografia. Brasília: XVIII Prêmio Tesouro Nacional, 2013. 51 p. Disponível em <https://sisweb.tesouro.gov.br/apex/apex_util.get_blob?s=10653654714585\&a=2521\&c $=1914535545846072815 \& \mathrm{p}=3 \& \mathrm{k} 1=1346 \& \mathrm{k} 2=\& \mathrm{ck}=X F B r k q a E k \_R f 0 d o O Q B M s C t H m-$ KAmtODyRVfyT5UQCa9cNm5Lg5iI3fjxraP8YYZMvUtJey2f1cdmGtkQxlG7TA\&rt= IR> acesso em 20 Nov. 2017.

PRAÇA, Sérgio. A organização do processo orçamentário nas Assembleias Legislativas brasileiras. In: Cadernos Gestão Pública e Cidadania, v. 17, n. 60, Jan-Jun, 2012, p. 123.

RAE, D. The Political Consequences of Electoral Laws. New Haven: Yale University Press, 1967. $173 \mathrm{p}$.

RIKER, J. Political Science and Rational Choice. In: JAMES, E. e KENENTH, A. S. (Orgs.). Perspectives on Positive Political Economy. Cambridge: Cambridge University Press, 1990. p. 163-181.

SANTOS, F. G. M. (Org). O Poder Legislativo nos Estados: Diversidade $e$ Convergência. Rio de Janeiro: Editora FGV, 2001. 308 p. 
SHEPSLE, K. A.; WEINGAST, B. Uncovered Sets and Sophisticated Voting Outcomes with Implications for Agenda Institutions. In: American Journal of Political Science, v. 28, n. 1, Feb. 1984, p. 49-74.

SHUGART, M. S.; CAREY, J. Presidents and Assemblies: Constitutional Design and Electoral Dynamics. Cambridge: Cambridge University Press, 1992. 332 p.

SANTOS, F. G. M.. O Poder Legislativo nos Estados: Diversidade e Convergência. 1a.. ed. Rio de Janeiro: Editora FGV, 2001. 308p

SOUZA, C. Federalismo, desenho constitucional e instituições federativas no Brasil pós-1988. Rev. Sociol. Polit., Curitiba, n. 24, p. 105-121, Junho 2005. Disponível em <http://www.scielo.br/scielo.php?script=sci_arttext\&pid=S0104-

$44782005000100008 \& \operatorname{lng}=\mathrm{en} \& n \mathrm{~nm}=$ iso>. acessado em 21 Nov. 2017.

TOMIO, F. R. L. e RICCI, P. Conexão Eleitoral, Processo Legislativo e Estratégias Parlamentares nas Assembleias Legislativas Estaduais. In: ENCONTRO NACIONAL DA ASSOCIAÇÃO BRASILEIRA DE CIÊNCIA POLÍTICA, 6., 2008, Campinas. 6 Encontro da ABCP. São Paulo: ABCP, 2008.

TOMIO, F. R. L.; RICCI, P. Instituições e decisões: estudo comparativo do processo legislativo nas Assembleias Estaduais. In: ENCONTRO NACIONAL DA ASSOCIAÇÃO BRASILEIRA DE CIÊNCIA POLÍTICA, 7., 2010, Recife-PE. 7 Encontro da ABCP - AT06 - Instituições Políticas. São Paulo: ABCP, 2010.

ZUCCO JR, C. Esquerda, Direita e Governo: A ideologia dos partidos políticos brasileiros. In: POWER, T.; ZUCCO Jr., C. (Org.). O Congresso Por Ele Mesmo. Belo Horizonte: Editora UFMG, 2011. p. 37-60.

Recebido em 3-07-2016;

Revisado em 24-04-2017;

Publicação em 04-05-2018. 